\title{
Implementation of maternal health financial scheme in rural Bangladesh
}

Md. Moshiur Rahman

Ubaidur Rob

Population Council

Tasnima Kibria

Population Council

Follow this and additional works at: https://knowledgecommons.popcouncil.org/departments_sbsr-rh

Part of the Demography, Population, and Ecology Commons, Family, Life Course, and Society Commons, Gender and Sexuality Commons, International Public Health Commons, Maternal and Child Health Commons, and the Medicine and Health Commons How does access to this work benefit you? Let us know!

\section{Recommended Citation}

Rahman, Md. Moshiur, Ubaidur Rob, and Tasnima Kibria. 2009. "Implementation of maternal health financial scheme in rural Bangladesh." Dhaka: Population Council. 


\title{
Implementation of Maternal Health Financial Scheme in Rural Bangladesh
}

\author{
Md. Moshiur Rahman \\ Ubaidur Rob \\ Tasnima Kibria
}

\section{Population Council, Bangladesh}

March 2009
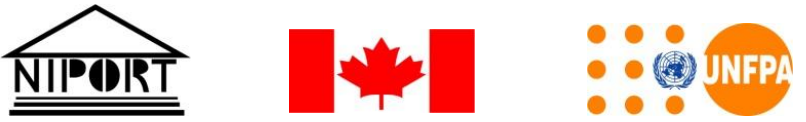


\section{ACKNOWLEDGEMENTS}

It is indeed our pleasure to acknowledge the collaboration and financial contributions made by the Canadian International Development Agency (CIDA) through the United Nations Population Fund (UNFPA). We acknowledge the support, commitment and technical assistance of NIPORT, CIDA and UNFPA. We express our sincere thanks to the project partners: RTM International and ICDDR, B.

We acknowledge the willingness of Central Hospital \& Diagnostic Center and BRAC Suswastho Hospital, Habiganj to participate in the study. Thanks also to the owners of district and upazila level commercial drug stores who supplied medicine to the clients in exchange for their vouchers.

We would like to thank district and upazila level government officials and the service providers who were partners in implementing the study. Service providers and staff of HFWCs, the Central Hospital \& Diagnostic Center and BRAC Suswastho Hospital, Habiganj played a critical role in the implementation process.

The authors are thankful to Dr. Ahmed Al-Sabir, Director (Research), NIPORT for his guidance and continued support at every step of the study. Besides being an active collaborator from NIPORT, his role as Coordinator of Demand Based Reproductive Health Commodity Project (DBRHCP) deserves special thanks. Appreciation is due to Dr. Shafiqur Rahman, UHFPO, UHC, Nabiganj for his continuous support in implementing the project activities smoothly.

We would also like to thank the members of district and upazila level coordination committees for their sincere participation for institutionalizing the process of voucher scheme. In addition, we would like to convey sincere gratitude to the local project staff and study team who participated in the data collection process.

Special thanks are due to the members of community support groups (CSGs) who participated in the study and organized monthly meetings without any financial gain.

We are also grateful to Dr. Ian Askew of Population Council, Kenya for reviewing the draft version of the report and providing useful comments.

Finally, we are thankful to Population Council colleagues for technical, administrative and logistical support. 


\section{AbBreviations}

\begin{tabular}{|c|c|}
\hline $\mathrm{AHI}$ & Assistant Health Inspector \\
\hline ANC & Antenatal Care \\
\hline APHA & American Public Health Association \\
\hline BCC & Behavior Change Communication \\
\hline BDHS & Bangladesh Demographic and Health Survey \\
\hline CIDA & Canadian International Development Agency \\
\hline CSG & Community Support Group \\
\hline DDFP & Deputy Director of Family Planning \\
\hline DGFP & Directorate General of Family Planning \\
\hline DGHS & Directorate General of Health Services \\
\hline DSF & Demand Side Financing \\
\hline EmOC & Emergency Obstetric Care \\
\hline FP & Family Planning \\
\hline FPI & Family Planning Inspector \\
\hline FWA & Family Welfare Assistant \\
\hline FWV & Family Welfare Visitor \\
\hline HA & Health Assistant \\
\hline HFWC & Health and Family Welfare Center \\
\hline $\mathrm{HI}$ & Health Inspector \\
\hline ICDDR, B & International Center for Diarrheal Diseases Research, Bangladesh \\
\hline MDG & Millennium Development Goal \\
\hline MMR & Maternal Mortality Ratio \\
\hline $\mathrm{MO}$ & Medical Officer \\
\hline MOHFW & Ministry of Health and Family Welfare \\
\hline $\mathrm{MO}-\mathrm{MCH}$ & Medical Officer-Maternal and Child Health \\
\hline NGO & Non Government Organization \\
\hline NIPORT & National Institute of Population Research and Training \\
\hline OR & Operations Research \\
\hline PAA & Population Association of America \\
\hline $\mathrm{PNC}$ & Postnatal Care \\
\hline PROGRESA & $\begin{array}{l}\text { Programa de Educación, Salud y Alimentación (The Education, Health and } \\
\text { Nutrition Program of Mexico) }\end{array}$ \\
\hline $\mathrm{RMO}$ & Residential Medical Officer \\
\hline RTI & Reproductive Tract Infection \\
\hline RTM International & Research Training and Management International \\
\hline SACMO & Sub Assistant Community Medical Officer \\
\hline SBA & Skilled Birth Attendant \\
\hline STI & Sexually Transmitted Infection \\
\hline UHFPO & Upazila Health and Family Planning Officer \\
\hline UNFPA & United Nations Population Fund \\
\hline UP & Union Parishad \\
\hline VMA & Voucher Management Agency \\
\hline WHO & World Health Organization \\
\hline
\end{tabular}




\section{EXECUTIVE SUMMARY}

The maternal mortality ratio in Bangladesh has declined from more than 600 per 100,000 live births in 1980 to 322 in 2004, yet it is still unacceptably high. Research indicates that economic barrier is one of the most important factors that deters pregnant women from seeking services at health facilities. To achieve the country's Millennium Development Goal of reducing the maternal mortality ratio to 143 by the year 2015, the Population Council conducted an operations research study to test the feasibility and effectiveness of introducing an innovative model of health care financing to increase the utilization by poor, rural women of maternal health services. The project objectives were: i) developing a system to distribute vouchers to poor rural pregnant women for maternal health care services; ii) identifying private and non-government organization facilities that can provide quality maternal health care services to poor pregnant women; iii) increasing the capacity of service providers in offering antenatal care (ANC), delivery and postnatal care (PNC) services; and iv) improving the level of utilization of antenatal care, delivery and postnatal care services from trained service providers by poor, rural pregnant women. The study used a pre- and post-test design to examine the effectiveness of the interventions in two unions of Nabiganj upazila of Habiganj district.

A 'voucher book' was designed through which a pregnant woman would be able to receive a package of essential maternal health care services, as well as treatment of pregnancy and deliveryrelated complications. The voucher book contains six separate types of vouchers:

1) Three antenatal care visits

2) Management of pregnancy and delivery-related complications

3) Delivery care

4) Postnatal care

5) Medicines

6) Transport allowances.

A voucher management agency (VMA) was created, in which RTM International was responsible for managing the financial aspects and Population Council for managing the technical aspects. The VMA constituted district and upazila voucher committees and transferred sufficient funds to these committees to cover the estimated costs of reimbursing providers for the services delivered. The VMA organized training programs to improve the skills of service providers and fieldworkers and strengthened health facilities for providing ANC, delivery and PNC services. Simultaneously, the VMA communicated with local stakeholders to form community support groups (CSGs). Fieldworkers identified pregnant women that qualified as eligible for receiving vouchers using predefined criteria of poverty and submitted the list of women to the CSGs for validation, after which the CSG returned the list to the fieldworkers. Fieldworkers received voucher books from the VMA and gave them to the pregnant women validated as eligible. In addition, fieldworkers and CSG members increased awareness within the community on the availability and importance of using maternal health services through flipcharts and pamphlets. Voucher recipients then accessed the services from the trained providers participating in the scheme by exchanging a voucher for the approved service. The service providers submitted the vouchers received, together with supporting documentation, to the upazila voucher committee for reimbursement; the committee paid the service providers the agreed amount for each voucher presented and approved. Because emergency obstetric care services are not provided at upazila level health facilities, services for pregnancy and delivery related complications could be accessed from district level health facilities and a district voucher committee managed reimbursement of vouchers for these services. 
Interventions undertaken to support the introduction of the vouchers included: i) strengthening capacity of service providers and fieldworkers, ii) improving physical infrastructure and ensuring necessary equipment at health facilities, iii) creating awareness through behavior change communication activities, and iv) involving local people through community support groups. These interventions were implemented for nine months, from October 2007 to June 2008.

To institutionalize the process of voucher scheme, coordination committees were formed at district and upazila levels with assistance from program managers and service providers. These committees selected non-government organizations and private clinics to participate in delivering services and in the financial reimbursement mechanism. In addition, community support groups comprising local people were formed at ward level for validating the eligibility of poor, pregnant women for receiving the vouchers. A total of 702 poor, pregnant women were identified by fieldworkers and among them 580 women were validated by the community support groups to receive the vouchers. The community support groups assisted the Ministry of Health and Family Welfare staff to strengthen the physical infrastructure of health facilities and to build trust between service providers and clients. Furthermore, the community support groups identified several service-related issues in their regular monthly meetings and informed the respective fieldworkers so that they could resolve the issues.

Health facility strengthening was essential for physically renovating infrastructure and ensuring the necessary equipment to provide normal deliveries were available. These activities increased the confidence of service providers as well as encouraged clients to receive services from the facility. Behavior change communication activities, including group sessions, drama shows and raffle draws, encouraged pregnant women to access the maternal health care services. Apart from their regular satellite sessions, fieldworkers and service providers organized several group sessions with the assistance of community support group members. They used flipcharts to make the sessions more informative and interactive. In addition, service providers and fieldworkers distributed pamphlets to the pregnant women. Observations suggest that the educational materials were effective in disseminating information on maternal health care services in the community.

Observations at facilities indicated that service providers were available and the infrastructure of the health facility was favourable. There were adequate behavior change communication materials and necessary equipment to provide quality maternal health care services. Service providers were observed maintaining privacy with clients during the consultations. A significant number of the voucher recipients reported receiving quality maternal health care services during the intervention period. Monitoring reports from the community support group monthly meetings indicate that the meetings were held in a participatory manner and specific issues were discussed. Apart from the Family Welfare Assistant, in most of the areas the male union parishad members played important roles in organizing meetings. Monitoring visits revealed that most of the union family planning committee meetings were not held due to the engagement of members in other priorities. However, when the interventions were being introduced they played an important role in strengthening the infrastructure of the health facilities.

The 21-day hands-on training session for the Family Welfare Visitors to perform normal deliveries at health and Family Welfare Centers was found appropriate. Three days training for the service providers and fieldworkers was reasonably effective for disseminating information on the importance of maternal health care issues and the process of administering the vouchers. This is an encouraging finding as it provides an opportunity for disseminating important information to the clients by fieldworkers during their routine household visits and voucher distribution. 
Findings from the endline survey revealed that knowledge on maternal health care issues, including life-threatening complications, sources of treatment for complications, place of safe delivery, intake of vitamin A capsule and duration of exclusive breastfeeding, had increased significantly compared to the baseline. The proportion of women who did not access any antenatal care services decreased from 21 to 11 percent and the proportion of women who received this service from a trained service provider increased from about 50 to 100 percent. Similarly, the proportions of women attending for first, second and third antenatal visits increased over time. A significant number of women received physical and medical examination facilities during antenatal care visits and immunization during pregnancy and supply of iron tablet/syrup also increased (from 63\% to $72 \%$ and $20 \%$ to $77 \%$ respectively).

Increasing the proportion of deliveries assisted by trained providers is essential to achieve the MDG of reducing the maternal mortality ratio. At baseline, trained providers attended only 5.5 percent of births, whereas at endline this proportion had increased to 22 percent. Similarly, the proportion of deliveries at health facilities increased to 18 percent from a baseline of 2.3 percent. The proportion of women who received treatment for complications also increased significantly over the intervention period.

The proportion of women who received postnatal care increased significantly to 60 percent at the endline; moreover, at the baseline, only one-fourth of women accessing postnatal care received it from trained providers, which increased to 100 percent at endline. The proportion of women using Vitamin A capsule has increased and the majority of women exclusively breastfed their baby immediately after delivery.

Although the proportions of women using antenatal care, postnatal care, institutional deliveries and deliveries assisted by trained providers increased significantly, it is important to note that these proportions remained relatively low after the intervention. The majority of women received vouchers during the later stages of their pregnancy (85 percent received them during the third trimester), which was due to the short duration of the intervention period and so had less opportunity to avail ANC services.

The most frequently cited reasons for not delivering at a health facility were: no problems (60 percent); labor pain started suddenly (25 percent); no-one to accompany them to the facility (14 percent); and fear (12 percent). Similarly, the most frequently cited reasons for not accessing PNC services were: didn't face any problems (17 percent); not sure about the system of voucher utilization (24 percent); providers reluctant to provide services (23 percent); fear (15 percent); and other service related-issues (17 percent).

In-depth interviews revealed that women did not experience any problems in obtaining the voucher book from the fieldworkers. Overall, they expressed positive perceptions of the service quality and behavior of the providers. Women did not report facing any problems in utilizing the services in exchange for the vouchers and they received the fixed transport and medicine cost allowances. On average, 667 Taka (US\$9.70) was spent per case, which is reasonable and affordable. 
Based on these findings, the following recommendations are made for scaling-up these activities in other areas of Bangladesh:

- Formation of coordination committees at district and upazila levels is essential to identify eligible health facilities and to establish reimbursement mechanism for the vouchers.

- Community support groups can play crucial roles for validating pregnant women identified as poor, as well as for identifying problems and finding possible solutions to strengthen the physical infrastructure and performance of union-level health facilities.

- Strengthening health facility in terms of instruments/equipment, furniture and medicines are an encouraging factor leading to the availability of quality services and the increased number of clients at the facility.

- Hands-on training increases the confidence of Family Welfare Visitors to perform normal deliveries at the Health and Family Welfare Centers. Training for service providers and fieldworkers is essential to update their knowledge and skills on maternal health care services and for orienting them on the process of utilizing vouchers.

- The process of identifying poor pregnant women and distribution of the vouchers needs to begin early in a pregnancy to ensure that the woman can benefit from the full range of services covered.

- Strong commitment from the service providers and fieldworkers is essential to improve the utilization of maternal health care services. To reduce the workload of female paramedics, male paramedics can be encouraged to undertake physical and medical examinations during pregnancy care and record-keeping for vouchers can be simplified. 


\section{TABLE OF CONTENTS}

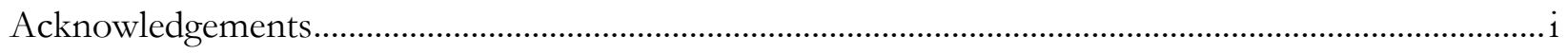

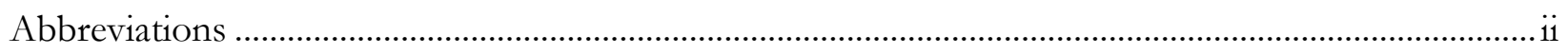

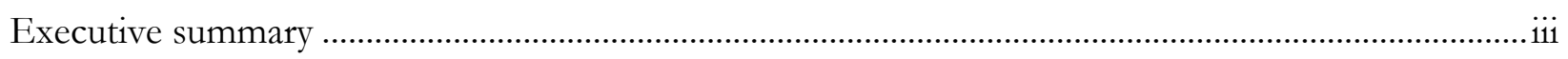

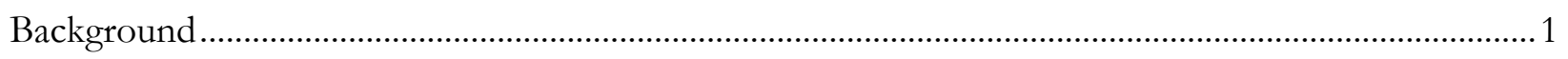

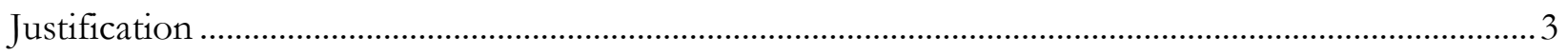

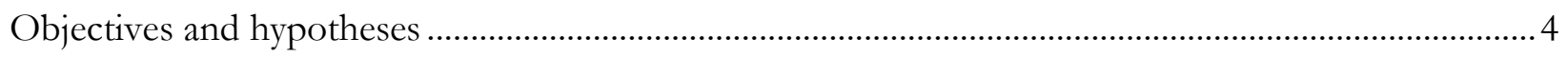

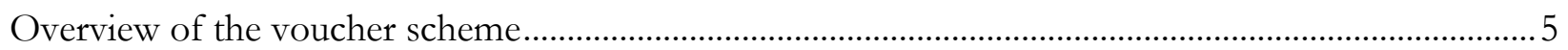

Intervention implementation ...........................................................................................

Preparatory activities ..........................................................................................................

Establishing the voucher reimbursement mechanism .............................................................................

Determining the cost of services and developing a voucher book and guidelines ...............................

Identification of private and NGO facilities as partner to provide services ........................................ 8

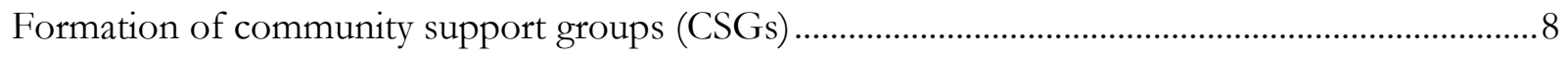

Eligibility criteria ......................................................................................................................

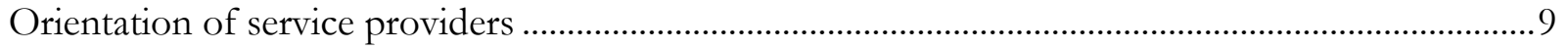

Capacity building of service providers and fieldworkers .................................................................10

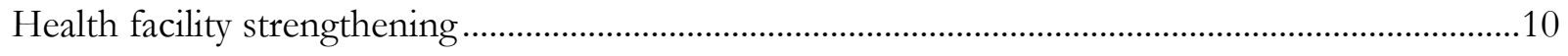

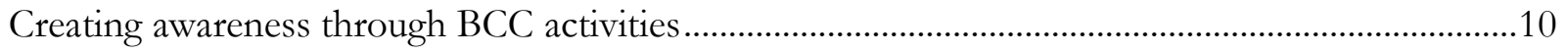

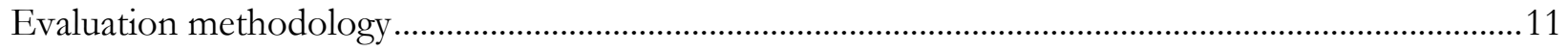

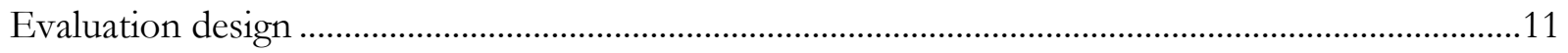

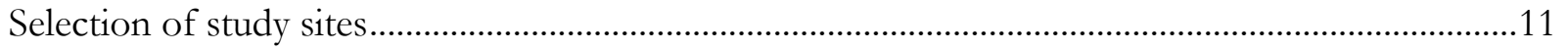

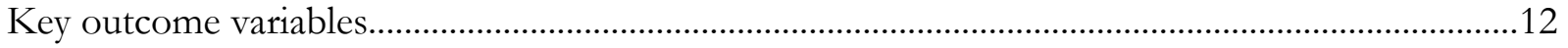

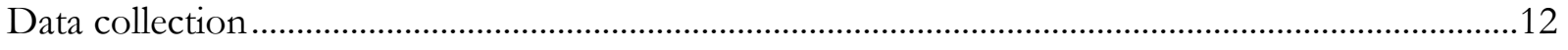

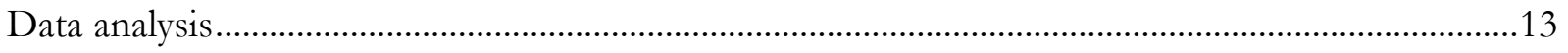

Assessment of the implementation process .................................................................................13

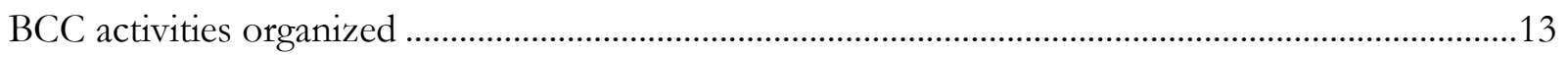

Facility readiness and service quality .....................................................................................14

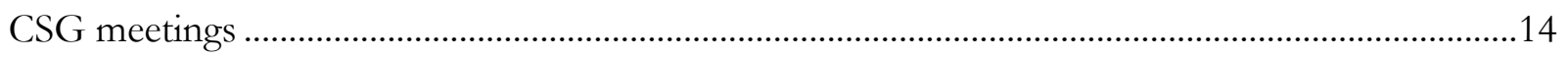

FP committee meetings ……………………………………………………………….....

Coordination committee members .................................................................................................15

Number of poor pregnant women received vouchers.......................................................................16 


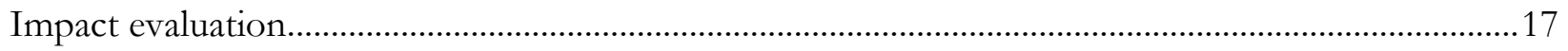

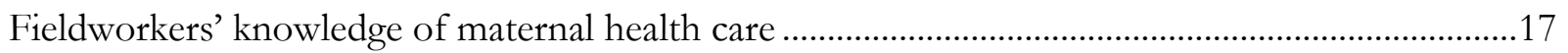

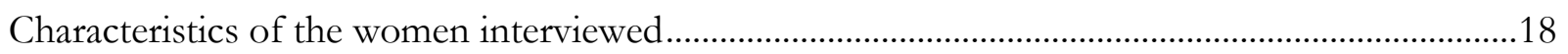

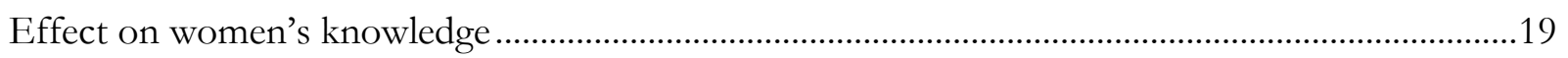

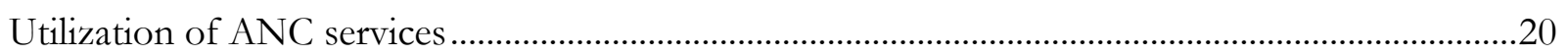

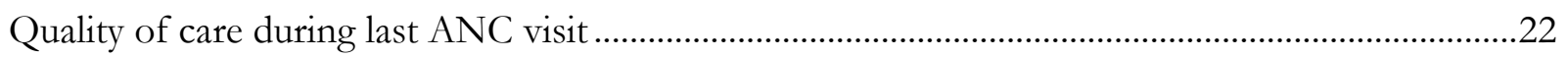

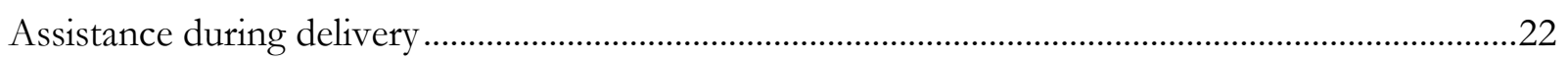

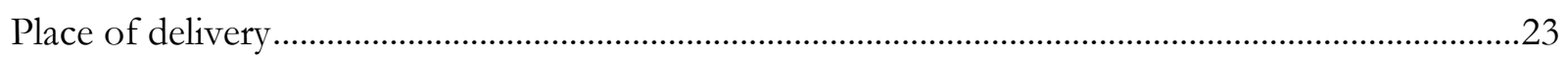

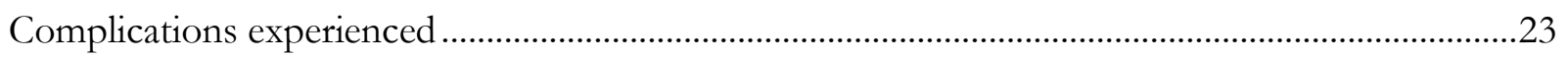

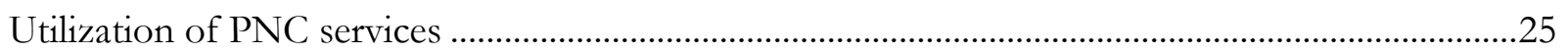

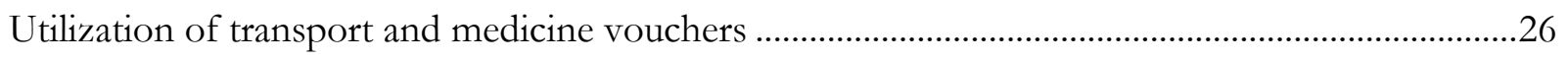

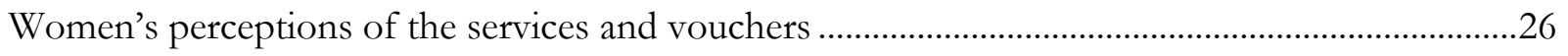

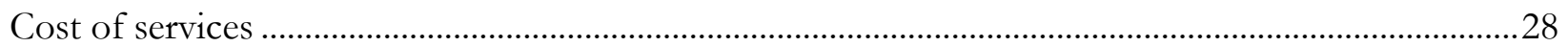

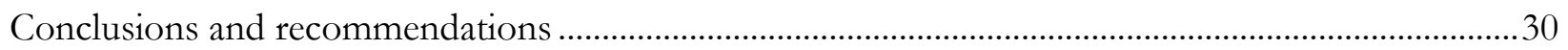

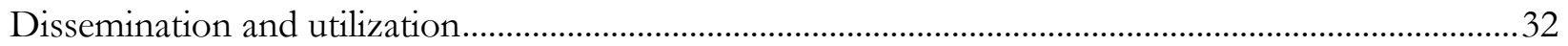

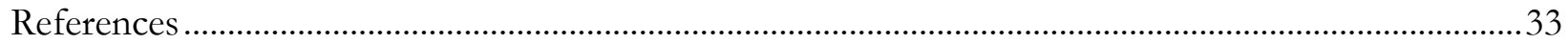




\section{LiST OF TABLES AND FIgURES}

Table 1: Price structure for maternal health care services package 8

Table 2: Number of group sessions organized by months 13

Table 3: Availability of services at HFWC (in percent) 14

Table 4: Findings from CSG meetings (in percent) 14

Table 5: Number of fieldworkers reported correct knowledge on maternal health care services 17

Table 6: Background characteristics of women and husbands (in percent) 18

Table 7: Demographic characteristics of women (in percent) 19

Table 8: Women's perceptions of life-threatening complications 19

Table 9: Providers consulted for ANC services (in percent) 21

Table 10: Services/examinations provided during ANC check-up (in percent) 21

Table 11: Quality of care addressed during last ANC visit (in percent) 22

Table 12: Persons assisting during delivery (in percent) 22

Table 13: Place of last delivery (in percent) 23

Table 14: Women's experiences of life-threatening complications during pregnancy, delivery and $\begin{array}{ll}\text { postpartum } & 24\end{array}$

Table 15: Utilization of PNC check-up (in percent) 25

Table 16: Cost of services provided 29

Figure 1: Functioning of the voucher management scheme 5

Figure 2: Number of pregnant women received vouchers 16

Figure 3: Correct knowledge on maternal health care issues by the fieldworkers (in percent) 17

Figure 4: Knowledge of sources of treatment for life-threatening complications (in percent) 20

Figure 5: Knowledge of sources of safe delivery (in percent) 20

Figure 6: Proportion of women attending ANC visit(s) 20 


\section{BACKGROUND}

The maternal mortality ratio (MMR) is not only an indicator of maternal health but also considered an important indicator of the overall health status and well-being of a nation. Bangladesh has made significant improvements in several related health indicators. The infant mortality rate has declined substantially from 110 per 1,000 live births in the mid-eighties to 65 per 1,000 live births in 2004 . The neonatal mortality rate declined from 52 in 1993 to 41 in 2004, which is largely attributable to an effective vaccination program - more than two-thirds of all children now receive all recommended vaccinations before their first birthday. In addition, the total fertility rate declined from more than six in 1975 to three in 2004 (NIPORT, Mitra Associates, and ORC Macro 2007). Nevertheless, although the maternal mortality ratio (MMR) has almost halved from more than 600 in 1980 to 322 in 2004, it is still one of the highest in the world. Regional variations in MMR are also observed within Bangladesh; for example, in the Rajshahi division, MMR is 223 whereas in the Sylhet division it is 471 (NIPORT et al. 2003). Therefore, special efforts are needed to address the regional variations in MMR in the country.

Pregnancy and delivery-related deaths account for 20 percent of all deaths among women of reproductive age in Bangladesh (NIPORT et al. 2003). Two-thirds of maternal deaths occur after delivery; one in ten occurs during delivery, and the remaining one in five occurs before delivery. The leading causes of maternal deaths are haemorrhage (29 percent) and eclampsia ( 24 percent). Other direct major causes of maternal deaths are prolonged/obstructed labor and puerperal sepsis. The non-availability of trained providers, low uptake of services by women, and infrastructure difficulties all contribute to the high rate of maternal deaths in Bangladesh.

Utilization of antenatal care (ANC) and postnatal care (PNC) services can reduce maternal mortality and morbidity significantly. However, the utilization of maternity care provided by trained professionals during and after delivery is alarmingly low in Bangladesh. While there has been some improvement in recent years, about half of all pregnant women do not seek any ANC (NIPORT, Mitra Associates, and ORC Macro 2007). The Government of Bangladesh recommends a minimum of three ANC visits, with one visit every three months. Only one in three pregnant women makes three or more ANC visits (NIPORT, Mitra Associates, and ORC Macro 2007). Among those who do access ANC, 31 percent receive services during the first trimester and 24 percent delay seeking care until the third trimester. The frequency of ANC visits and early initiation of ANC is higher among women with first births, women in urban areas, those who have completed secondary school, and those from the wealthiest households (NIPORT, Mitra Associates, and ORC Macro 2005).

Approximately half of all women receive ANC from trained or untrained providers (NIPORT et al. 2003). The main providers of ANC are doctors ( 24 percent) and trained paramedics ( 15 percent). Reasons for not seeking ANC include perceptions that the service is not necessary (62 percent) and monetary constraints (21 percent) (NIPORT et al. 2003). Other reasons are familial or religious constraints, non-availability of transport and service-related issues.

To reduce the health risks for mothers and their babies, it is important to increase deliveries by skilled providers with adequate medical supervision (Graham, Bell and Bullough 2001). Yet, delivery at home remains almost universal; about 85 percent of babies are born at home in Bangladesh. Seven percent of deliveries occur in public health facilities and eight percent in private hospitals and 
clinics. Trained providers (doctors, trained nurses or midwives, or paramedics) attend only 15 percent of deliveries (NIPORT, Mitra Associates, and ORC Macro 2007). Only 29 percent of women with complications during delivery receive treatment from trained providers; 33 percent visit unqualified providers. The remaining one-third do not seek any care for maternal complications (NIPORT et al. 2003; NIPORT, Mitra Associates, and ORC Macro 2005). The proportion of institutional deliveries is higher among women of higher socio-economic status, women in urban areas, and women with secondary school or higher education (NIPORT et al. 2003; NIPORT, Mitra Associates, and ORC Macro 2007).

Several social, religious and economic barriers prevent women from seeking services during delivery at health facilities. Frequently-cited reason for not delivering in a facility is perceived absence of need (68 percent) followed by the cost of treatment (18 percent) (NIPORT et al. 2003). Other cited reasons include poor quality of services and lack of access or transportation problems. Less educated and poorer women are more likely to report cost as a reason for choosing not to deliver at health facilities.

Only 21 percent of mothers get any postnatal checkups from trained providers within 42 days of delivery. Most women are checked up within the first two days after delivery (NIPORT, Mitra Associates, and ORC Macro 2007). The percentage of postnatal checkups is lower among women in rural areas, in those from lower socio-economic status, and in those who have no education (NIPORT, Mitra Associates, and ORC Macro 2007). The primary reason for not receiving a postnatal check-up is the perceived absence of need (56 percent) followed by cost of treatment (22 percent). Older women, women with higher parity, those with lower education, and those in poorer households report cost as a barrier for not seeking postnatal care (NIPORT et al. 2003).

According to the "Three Delays" model, cost is one of the most important factors that affect decisions related to care seeking. Rob et al. (2006) also found that cost was one of the most important barriers for not seeking ANC and PNC services in Bangladesh. They suggested providing financial support to poor women to reduce catastrophic health expenditures, especially for delivery, reproductive tract infections (RTIs), and sexually transmitted infections (STIs) related services.

Several reasons for the low utilization of maternal health care have been documented (Rahman et al. 2006). The two main reasons are lack of knowledge about maternity care services (including antenatal, delivery and postnatal care) and economic barriers while seeking treatment from qualified service providers. These findings clearly indicate the need to improve maternal health services through the provision of education, counselling, referrals, and by providing financial support to poor women.

A training needs assessment survey conducted by Research Training and Management International (RTM International) revealed that many service providers require training to improve their knowledge and skills in maternal health services including their counselling skills (RTM International 2006). Referral systems need to be set up for managing pregnancy and delivery-related complications.

1 The 'Three Delays' model identifies three factors that may delay a pregnant woman accessing services: i) delay at home in deciding whether to seek medical care; ii) delay on the road to reach the qualified medical practitioners or institutions; and iii) delay in receiving services after reaching the facility. 
It is now acknowledged that maternal health programs have failed to serve a large portion of the poor and vulnerable groups in rural areas. Supply-side barriers include: the non-availability of doctors and drugs; discriminatory behavior of providers; and lack of an effective cost-exemption mechanism. There are also demand-side barriers that inhibit women from seeking ANC, delivery and PNC services, including lack of information about when or from where to obtain treatment and women's awareness of potentially life-threatening conditions during pregnancy, delivery and after delivery (NIPORT, Mitra Associates, and ORC Macro 2005). Other obstacles to seeking treatment include high indirect costs, transportation costs, intra-household preferences, and socio-cultural norms (Ensor 2002; Rob et al. 2006). Due to these many reasons, most deliveries are performed by untrained person that results high maternal mortality.

The Bangladesh Health and Population Sector Program aims to reduce maternal mortality and morbidity by focusing on emergency obstetric care (EmOC). The aim is to detect women who have complications and refer them to facilities that provide quality services (Ministry of Health and Family Welfare 2001). Although the Government has pledged to provide safe motherhood services, it has yet to introduce risk-sharing mechanisms to support the poor.

Several non-government organizations (NGOs) are implementing innovative initiatives for reducing the financial burden on the poor, including health insurance and subsidized health cards. Limited curative care services, ANC, PNC, annual health checkups, medicines and laboratory services are being provided. Though these schemes have been in operation for many years, they reach only a small proportion of the population. A major weakness has been that beneficiaries do not have a preference about the provider. Most of the schemes are covering risks that are high in terms of frequency, but low in terms of costs. On the other hand, catastrophic illnesses are low in frequency and high in terms of cost. Most of these schemes do not have adequate coverage to offset these vulnerability factors (Islam 2003). Moreover, service providers are reluctant to make subsidized/free services available due to the pressure to increase cost recovery (Islam 2003).

\section{JUSTIFICATION}

Financial assistance through a subsidized voucher model could enable the poor to receive maternal health care services. This system has already been tested in several countries. In Nicaragua, a voucher scheme was used for the prevention and treatment of STIs. Findings suggest positive effects among the target group regarding utilization of key preventive health services (Borghi et al. 2005). Bhatia et al. (2006) showed that this scheme could also be an option for increasing the utilization of reproductive and child health services in India. In the Yunnan Province of China, a voucher scheme was introduced for low-income, pregnant women to increase the utilization of maternal and child health services. This scheme covered the cost of ANC, delivery and PNC as well as care of sick children. Preliminary findings show that the distribution of vouchers has increased the utilization of treatment for childhood diarrhoea among the poor (Kelin, Zhang and Tang 2001). In Mexico, the program, PROGRESA, combines a conditional cash transfer with financial incentives for families to invest in health, education and nutrition of children. Families are encouraged to obtain preventive health care, participate in growth monitoring and nutrition supplements programs and attend health education programs to be eligible for cash transfer. The study findings showed a significant improvement in the health of both children and adults (Gertler and Boyce 2001). Experience with a discount voucher for insecticide treated bed-nets in Tanzania showed higher utilization of bed-net by poor, pregnant women and young children (Marchant et al. 2002; Mushi et al. 2003). 
Government health facilities located in rural areas of Bangladesh provide free ANC, delivery and PNC services, but the related costs of medicines, transportation and treatment for complications discourages many poor women from seeking these services. To achieve the Millennium Development Goal (MDG) of reducing maternal mortality to 143 by the year 2015, therefore, a significant change in the health care seeking and service utilization behaviors of pregnant women is critical.

This report describes an operations research (OR) study undertaken by the Population Council under the Demand Based Reproductive Health Commodity Project (DBRHCP) to examine the effect on utilization of maternal health care services, delivered by trained providers, through providing financial support directly to poor pregnant women through vouchers. Aiming to improve the quality of health service delivery, and particularly of reproductive health services, the National Institute of Population Research and Training (NIPORT) has implemented DBRHCP with four partners with financial assistance from the Canadian International Development Agency (CIDA) and technical assistance from United Nations Population Fund (UNFPA).

\section{OBJECTIVES AND HYPOTHESES}

The overall objective of the study was to test the feasibility and effectiveness of introducing a voucher scheme for poor, rural pregnant women in order to improve their utilization of ANC, delivery and PNC from trained service providers. The specific objectives were to:

1. Develop a system to distribute vouchers to poor, rural pregnant women for maternal health care services

2. Identify private and NGO facilities for providing quality maternal health care services to poor pregnant women

3. Increase the capacity of service providers in offering ANC, delivery and PNC services

4. Improve the level of utilization of ANC, delivery and PNC services from trained service providers by poor, rural pregnant women.

The following three hypotheses were tested:

1. Introduction of the voucher scheme for poor, rural women will increase utilization of ANC, delivery and PNC services provided by trained service providers

2. Training will improve the capacity of service providers in providing ANC, delivery and PNC services

3. BCC and awareness raising activities will increase voucher recipients' knowledge and change their attitudes favourably towards seeking ANC, delivery and PNC from trained service providers. 


\section{OVERVIEW OF THE VOUCHER SCHEME}

A voucher management agency (VMA) was created, in which RTM International was responsible for managing the financial aspects and Population Council for managing the technical aspects. The VMA, in consultation with district and upazila level government officials, constituted district and upazila voucher committees and transferred sufficient funds to these committees (Step 1) to cover the estimated costs of reimbursing providers for the services delivered. The VMA organized training programs to improve the skills of service providers and fieldworkers and strengthened health facilities for providing ANC, delivery and PNC services (Step 2a). Simultaneously, the VMA communicated with local stakeholders to form community support groups (CSGs) (Step 2b). Fieldworkers identified pregnant women that qualified as eligible for receiving vouchers using predefined criteria of poverty and submitted the list of women to the CSGs for validation (Step 3a), after which the CSG returned the list to the fieldworkers (Step 3b).

Fieldworkers received voucher books from the VMA and gave them to the pregnant women validated as eligible (Step 4). In addition, fieldworkers and CSG members increased awareness within the community on the availability and importance of using maternal health services through flipcharts and pamphlets. Voucher recipients then accessed the services from the trained providers participating in the scheme by exchanging a voucher for the approved service (Step 5). The service providers submitted the vouchers received, together with supporting documentation, to the upazila voucher committee for reimbursement (Step 6); the committee paid the service providers the agreed amount for each voucher presented and approved (Step 7). Because emergency obstetric care services are not provided at upazila level health facilities, services for pregnancy and delivery related complications could be accessed from district level health facilities and a district voucher committee managed reimbursement of vouchers for these services.

\section{Figure 1: Functioning of the voucher management scheme}

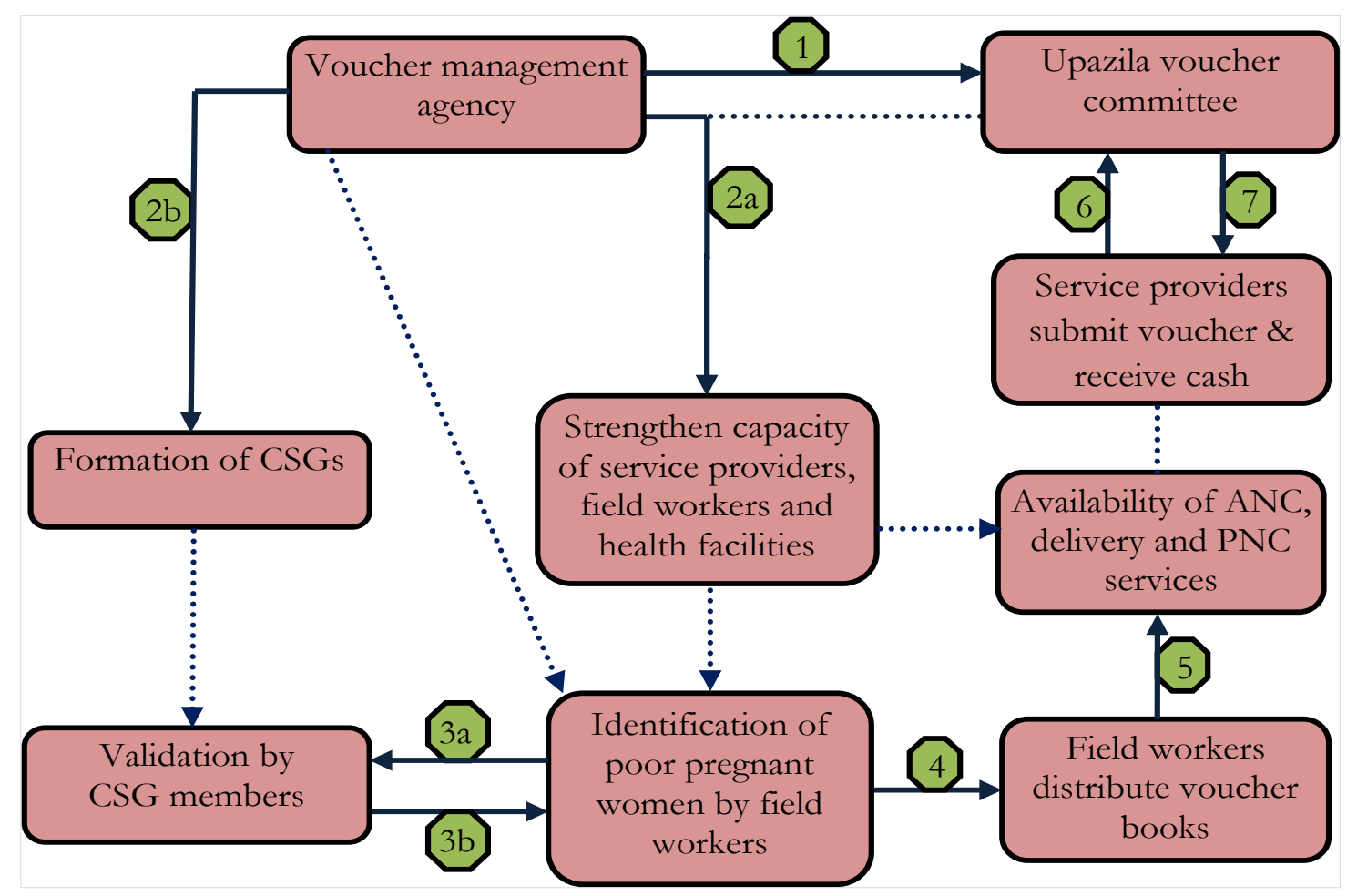




\section{INTERVENTION IMPLEMENTATION}

\section{Preparatory activities}

Workshop with district and upazila level program managers: An orientation workshop was organized for the district and upazila level managers and service providers to share the objectives, implementation plan and strategy of the project. In addition, coordination committees were formed to implement the project activities. Participants at the workshop included the Civil Surgeon (CS), Deputy Director of Family Planning (DDFP), Deputy Civil Surgeon (DCS), Consultant Gynaecology Department, District Hospital, Medical Officer (Clinic), Maternal and Child Welfare Center (MCWC), Upazila Health and Family Planning Officer (UHFPO), Upazila Family Planning Officer (UFPO), Medical Officer Maternal and Child Health - Family Planning (MCH-FP), Residential Medical Officer (RMO) and Medical Officers of Upazila Health Complex, Nabiganj.

Formation of coordination committees: Union and upazila level government health facilities in Nabiganj did not have EmOC services and so qualified NGO and private facilities, in addition to the MCWC and District Hospital, were identified for providing EmOC services. At the orientation workshop, district and upazila level committees were formed to select facilities interested in and capable of providing EmOC services. At the district level, the CS was the chairperson, the DDFP the vice chairperson, and the RMO as member secretary of the voucher committee. Other members of the district level committee were: DCS, Additional Director-Clinical Contraception, Consultant Gynaecology, Medical Officer (Clinic) of MCWC, and UHFPO and UFPO from Nabiganj upazila. In addition to selecting the eligible facilities, the committee was also responsible for:

- Meeting once a month to oversee the progress of the project

- Monitoring voucher distribution and provision of maternal health care

- Establishing and monitoring procedure for financial reimbursement.

An eight-member 'upazila voucher committee' was formed to support the project activities at upazila level. The committee was chaired by the Upazila Nirbahi Officer and the RMO was acting as the member secretary of the committee. The other members of the upazila level committee were: UHFPO (Vice-Chairperson), UFPO, MO-MCH (FP), Women Affairs Officer, and Chairpersons of Bausha and Gaznaipur Union. The terms of reference of the committee were as follows:

- Meet once a month to oversee the progress of the project

- Assist community support groups and service providers to identify poor women

- Monitor voucher distribution and provision of maternal health care services

- Review monthly progress on voucher distribution and service utilization

- Establish and monitor mechanism for financial reimbursement.

An upazila level 'technical support committee' was also formed to monitor the technical and financial issues of the voucher scheme. They also met urgently, if required, to solve any technical and financial issues instantly in the absence of upazila voucher committee members. This committee was accountable to upazila voucher committee. The members were: UHFPO, RMO and MO-MCH (FP) of Nabiganj UHC. 
Reactivating the Union Family Planning Committee (UFPC): The Government has constituted a FP Committee in each union to monitor and supervise health and family planning activities. For the past several years, most of the committees have become inactive or are irregular in discharging their assigned activities. The project staff contacted the committee members of UFPCs and requested them to participate in monitoring activities.

\section{Establishing the voucher reimbursement mechanism}

Instead of giving cash payments to women or providers, pregnant women received the maternal health services from the selected service providers in exchange for a voucher (Rahman 2008a). The medical officer at the upazila level maintained an account and service providers received payment when they submitted the vouchers from these designated persons. Similarly, expenses related to the costs of transportation and medicines were reimbursed by these designated persons to the transport owners and drug store owners on submission of the vouchers. The same approach was followed at the district level.

\section{Determining the cost of services and developing a voucher book and guidelines}

A 'voucher book' was designed through which a pregnant woman would be able to receive a package of essential maternal health care services, as well as treatment of pregnancy and deliveryrelated complications. The voucher book contains six separate types of vouchers:

1) Three antenatal care visits

2) Management of pregnancy and delivery-related complications

3) Delivery care

4) Postnatal care

5) Medicines

6) Transport allowances.

Guidelines for distributing the vouchers were developed for the service providers and fieldworkers. These guidelines focused on the distribution process, types of services available and the cost of services. The existing government payment structure for its demand side financing (DSF) project was used by the district and upazila voucher committee members as the basis for determining the cost of each service to be reimbursed to providers. Table 1 shows the maximum amount of money available for the provision of the recommended maternal health care services at any selected health facility.

Transportation costs are one of the major concerns for poor women during utilization of maternal health care from trained service providers. Therefore, vouchers for reimbursement of transportation costs were included for three ANC visits, delivery care including referral for complications, and one PNC visit. The costs of purchasing the required medicines from the commercial sector were also covered by a voucher. Despite having the costs of each service covered, there remained the risk of pregnant women experiencing critical life threatening complications which would incur additional costs for the treatment. For this reason, women were also encouraged to save their own money and a money savings box (coin box) was provided to each pregnant woman. 
Table 1: Price structure for maternal health care services package

\begin{tabular}{|c|c|c|c|c|}
\hline Services & Number & $\begin{array}{c}\text { Cost per } \\
\text { service (Tk.) }\end{array}$ & $\begin{array}{c}\text { Cost for } \\
\text { medicines (Tk.) }\end{array}$ & $\begin{array}{l}\text { Total cost } \\
\text { (Tk.) }\end{array}$ \\
\hline Blood test & 2 & 50 & na & 100 \\
\hline Urine test & 2 & 25 & na & 50 \\
\hline ANC visit & 3 & 50 & na & 150 \\
\hline PNC visit & 1 & 50 & na & 50 \\
\hline Normal delivery & 1 & 300 & na & 300 \\
\hline Medicine for normal delivery & 1 & na & 200 & 200 \\
\hline Forceps/Manual removal of placentas & & & & \\
\hline /D\&C/Vacuum extraction & 1 & 500 & 500 & 1000 \\
\hline Complications management & 1 & 500 & 1000 & 1500 \\
\hline $\begin{array}{l}\text { Caesarean delivery } \\
\text { Transportation costs for checkups }\end{array}$ & 1 & 4000 & 2000 & 6000 \\
\hline ANC & 3 & 100 & na & 300 \\
\hline $\begin{array}{l}\text { PNC } \\
\text { Transportation costs for Delivery/ }\end{array}$ & $\begin{array}{l}3 \\
1\end{array}$ & 100 & na & 100 \\
\hline $\begin{array}{l}\text { Complication management } \\
\text { Residence to union }\end{array}$ & 1 & 100 & na & 100 \\
\hline Union to upazila & 1 & 300 & na & 300 \\
\hline Residence to upazila & 1 & 400 & na & 400 \\
\hline $\begin{array}{l}\text { Residence to district/Union to } \\
\text { district/Upazila to district }\end{array}$ & 1 & $500-1000^{*}$ & na & $500-1000^{*}$ \\
\hline
\end{tabular}

\section{Identification of private and NGO facilities as partner to provide services}

The preliminary selection criteria to identify qualified private and NGO providers/facilities that can effectively perform normal and surgical delivery were prepared in consultation with officials from the Directorate General of Health Services (DGHS). The selection criteria were finalized considering the suggestions given by the program managers and service providers at the orientation workshop. The district level voucher committee members, along with staff from Population Council and RTM International, visited several health facilities and identified one private and one NGO hospital to provide pregnancy care under voucher scheme. The committee members met the management authority of these facilities to inform them about the process of the voucher scheme and received their consent for participating in the study. A memorandum of understanding (MOU) was signed between CS and owners of private and NGO facilities.

\section{Formation of community support groups (CSGs)}

To ensure sustained community involvement, one CSG was formed in each ward with male and female local government representatives and fieldworkers as focal persons. With the help of these focal persons, 18 CSGs were formed in the two unions. Each CSG consists of approximately seven to eleven members (Rahman 2008a). The elected representatives of the local government (Union Parishad) and fieldworkers (FWA/HA) in each ward were purposively selected as the members of the CSG. Other members of the CSGs were religious leaders, teachers, social activists, traditional birth attendants, rich and poor community members. The fieldworker was selected as member secretary and was responsible for organizing monthly meetings and maintaining required information. 
A half-day orientation workshop was organized for CSG members to inform them about the project activities and to orient them about their roles and responsibilities. The following issues were discussed in the workshops:

- Selection process of poor pregnant women and voucher distribution system.

- Available services and name of health facilities/providers participating in the study.

- Mode of transportation and allowances.

- Amount available for medicines and places from where it can be obtained.

- Cost reimbursement process.

- How to organize a successful monthly meeting.

\section{Eligibility criteria}

Identifying the poorest of the poor is a challenging, complex and difficult process. It is evident that collecting accurate information on income or consumption is difficult, especially in Bangladesh and so in most cases proxy indicators are being used. After reviewing criteria that have been adopted by organizations working in Bangladesh in providing subsidized health care services among the poor, some easily usable criteria were selected (Box 1). If a household met any two of these four criteria, then any pregnant woman in that household was

Box 1: Eligibility criteria

- Owns land less than 10 decimals

- Lives on daily-wage

- Resides in a small (one or two room) and/or thatched house

- One or more school-going aged children work for earning and thus cannot attend school. considered as poor and so eligible to receive the voucher book. Fieldworkers followed these criteria to prepare a list of the poorest pregnant women in the project areas as the first step for preparing a list of potential voucher recipients. This process included the opinions of community stakeholders since active involvement of community members was expected at every stage. The lists were then validated in consultation with the CSG members in their monthly meeting for voucher distribution.

\section{Orientation of service providers}

A total of three half-day orientation meetings were organized at district and upazila levels for service providers. The first meeting was organized with union and upazila level service providers, fieldworkers and their supervisors at upazila level. The second meeting was organized with district level government service providers, while the third one with private and NGO service providers. The participants were oriented on the objectives of the study, the process of selecting poor women, types of services available under voucher scheme, record keeping system and reimbursement mechanism for vouchers. 


\section{Capacity building of service providers and fieldworkers}

With technical assistance from Population Council, RTM International organized training sessions for service providers and fieldworkers. Two FWVs from the selected HFWCs received a three-week hands-on training from staff at the obstetric and gynaecological department of the district hospital in performing normal deliveries at an HFWC. In addition, project staff oriented them in the record keeping system and voucher reimbursement process. Three service providers and 23 fieldworkers attended a threeday training course on maternal health care services, counselling, use of BCC materials and

\author{
Box 2: Contents of fieldworkers training \\ $\checkmark$ ANC, delivery and PNC \\ $\checkmark$ Pregnancy and delivery related complications \\ $\checkmark$ Counseling \\ $\checkmark$ Referral and importance of follow-up visits \\ $\checkmark$ Distribution of BCC materials, and \\ $\checkmark$ Record keeping system and reimbursement \\ process of vouchers.
} record keeping system of vouchers (see Box 2).

All the service providers and fieldworkers were interviewed before and after the interventions. Survey findings revealed that the mean age of service providers and fieldworkers was 42 and 43 years respectively during baseline and endline survey. Sixty percent service providers and fieldworkers were female. On average, they have been providing services around 20 years.

\section{Health facility strengthening}

The existing infrastructure of health facilities was strengthened to enable the provision of quality services, especially for the management of complications related to pregnancy and delivery. On the basis of the situation analysis of facilities, RTM International, in collaboration with the officials of MOHFW, ensured that the HFWCs were fully equipped with the necessary instruments and equipment for providing normal delivery care services. The infrastructure of the facilities was improved through financial support from the UFPCs and CSGs. BCC materials were supplied to each health facility. To ensure clients' privacy, a system was introduced, whereby clients entered the provider's room for receiving services in an orderly manner. In addition, a signboard listing the services available and service hours was placed at the entrance of each health facility.

\section{Creating awareness through BCC activities}

In consultation with the appropriate government officials, the Population Council and RTM International developed, field-tested and printed one flipchart and two pamphlets. The flipchart was developed to increase awareness among pregnant women and community members on maternal health care services during education activities. One pamphlet was developed for community members that focused on signs of pregnancy, care during pregnancy, general problems and complications during pregnancy, pregnancy risks, balanced diet, standard ANC and PNC visit schedule and preparation for safe delivery. The other pamphlet was developed to focus on the importance of breastfeeding. In addition, Population Council and RTM International developed a poster focusing the importance of attending for consultations during pregnancy, delivery and after delivery, along with improving the quality of the existing poster which highlighted five danger signs of pregnancy. 
The Family Welfare Assistants (FWAs) used the flipchart to educate community members in group meetings, and distributed pamphlets during home visits. A total of 35 flipcharts and 2,000 pamphlets (1,000 for each union) were distributed to service providers and fieldworkers for distribution among community members and 16 posters were distributed to the health facilities. In addition to satellite sessions, with the assistance of CSG members, fieldworkers and service providers organized group sessions in the community with the aim of increasing awareness on maternal health care services among the pregnant women and community members. With the assistance of CSG members, service providers and fieldworkers organized several dramas in the community and raffle draw at HFWCs.

\section{EVALUATION METHODOLOGY}

\section{Evaluation design}

A pre- and post-intervention only design was used to examine the effect of fully subsidizing the cost of maternal health services through the provision of vouchers on the utilization of ANC, delivery and PNC services by poor pregnant women. A similar design was used to evaluate the effect of the capacity-building interventions on maternal health care providers' knowledge and skills. The duration of the intervention was nine months.

\section{Selection of study sites}

Bangladesh is administratively divided into six divisions, 64 districts, and 508 upazilas (BBS 2007). On average, each upazila has nine unions, which is the lowest administrative unit covering a population of approximately 25,000 to 30,000 . A union is divided into nine administrative units known as wards. From each union thirteen persons are elected as representatives including a chairperson, one male from each ward and one female from every three wards. At the union level, health and family planning services are provided through the Health and Family Welfare Center (HFWC). At this facility, services are provided by one female Family Welfare Visitor (FWV) and one male Sub-Assistant Community Medical Officer (SACMO). In addition, five to six Family Welfare Assistants (FWAs) and three Health Assistants (HAs) provide domiciliary services in each union. The Family Planning Inspector (FPI) and Assistant Health Inspector (AHI) work as supervisors of the FWA and HA respectively.

Because of the low use of FP services and high fertility rates, Nabiganj and Raipur upazilas in Habiganj and Lakshmipur districts respectively were selected for the DBRHC project. To facilitate implementation of the interventions, Bausha and Gaznaipur unions from Nabiganj upazila were purposively selected as the intervention sites considering the following criteria:

- Presence of female paramedics at HFWCs

- Availability of fieldworkers

- HFWCs are near to upazila health complex (UHC). 


\section{Key outcome variables}

As stated in the hypotheses, the project interventions were expected to have effects on two different populations:

Providers: Measured in terms of their knowledge about maternal health care services and the quality of services provided.

\section{Pregnant women (service clients):}

Knowledge

- Life-threatening complications during pregnancy, delivery and after delivery

- Sources of ANC, delivery and PNC services

- Knowledge of required number of ANC visits

- Intake of vitamin A capsule

- Knowledge on breastfeeding.

\section{Behavior}

- Utilization of ANC, delivery and PNC services

- Sources of ANC, delivery and PNC

- Visits to a health facility for management of complications

- Physical and medical examinations during an ANC visit

- Immunization

- Intake of iron tablets/syrup and vitamin A capsule

- Breastfeeding.

\section{Data collection}

Service provider and fieldworker survey: To assess the impact of training and knowledge gained by the service providers and fieldworkers, data were collected before and after introduction of the interventions. Surveys of all the providers (3 clinic providers and 23 fieldworkers) in the study area were conducted using a structured questionnaire before introduction of interventions and the same instruments were used ten months after the training to assess retention of knowledge.

Surveys of pregnant women: A baseline survey was conducted to measure the effects of the interventions. Mothers who had a child less than one year old were identified and classified into two groups, 'poor' and 'non-poor' through a principal components analysis using household enumeration information collected in the study areas by ICDDR, B. Using a simple random sampling procedure, 436 participants were selected from the 889 poor mothers identified (220 from Bausha and 216 from Gaznaipur) and interviewed about their health care practices during their last pregnancy. To assess the impact of the interventions on the population after they had been introduced, information was collected from 414 randomly selected poor women (243 from Bausha and 171 from Gaznaipur) out of the 580 women who had received a voucher book and who gave birth during the intervention period.

In-depth interviews: To collect detailed information about the mechanism of voucher distribution and utilization, in-depth interviews were conducted with 15 women who used maximum number of 
the vouchers while receiving ANC, delivery or PNC services. In addition, in-depth interviews were conducted with 15 women who did not use any vouchers to find out the reasons for their non-use.

\section{Data analysis}

Qualitative data were analyzed using content and descriptive analysis, and significance tests were used for the before and after comparisons of data from the provider and women surveys. The baseline and endline data were analyzed to examine the effectiveness of the interventions, and specifically their impact on knowledge and utilization of ANC, delivery and PNC services. Mean and proportionate tests were used to measure differences in the key outcome variables.

\section{ASSESSMENT OF THE IMPLEMENTATION PROCESS}

\section{BCC activities organized}

Drama shows: With the assistance of CSG members and fieldworkers, a cultural group organized drama shows, aimed at increasing awareness of maternal health care services. During January to June 2008, a total of 10 drama shows were staged, each attended by approximately 150 community members. The shows focused on the importance of utilizing maternal health care services from a health facility. Six key messages

Box 3: Topics addressed in drama shows

- Family planning

- Maternal health

- Early marriage

- Reproductive health

- Service provider and Fieldworker's activities

- Role of community people to promote health care services.

(Box 3) were disseminated several times by the actors. Community members suggested arranging more shows, indicating a positive response to these activities.

Raffle draw at HFWCs: Raffle draws were organized at each health facility to encourage the clients to receive the services from the health facilities. The clients who received services for general curative care, family planning, reproductive tract or sexually transmitted infections (RTI/STIs) or maternal and child health care were provided a coupon that they dropped into a box. After three months, a raffle draw was organized at each HFWC by the service providers and fieldworkers with the assistance of CSG members and in the presence of a large number of clients. A total of 33 clients received prizes at each HFWC.

Educational sessions: Apart from regular satellite sessions, fieldworkers and service providers, with the assistance of CSG members, organized 39 group sessions during October 2007 to May 2008 (Table 2). On an average, 14 women attended each group session. Fieldworkers used flipchart to make the sessions more informative and interactive. They focused on the importance of receiving maternal health care services from the health facility, the three delays that cause maternal deaths, five danger signs of pregnancy, use of voucher book, service center related issues, and family planning issues. CSG members also actively participated

\begin{tabular}{|ccc|}
\hline \multicolumn{3}{|c|}{$\begin{array}{c}\text { Table 2: Number of group sessions } \\
\text { organized by months }\end{array}$} \\
\hline Months & $\begin{array}{c}\text { No. of } \\
\text { sessions }\end{array}$ & $\begin{array}{c}\text { No. of } \\
\text { participants }\end{array}$ \\
\hline Oct `07 & 2 & 43 \\
Nov `07 & 13 & 196 \\
Dec `07 & 4 & 46 \\
Jan `08 & 2 & 24 \\
Feb `08 & 2 & 32 \\
Mar `08 & 9 & 117 \\
Apr `08 & 3 & 36 \\
May `08 & 5 & 67 \\
Total & $\mathbf{3 9}$ & $\mathbf{5 4 4}$ \\
\hline
\end{tabular}


in group sessions to motivate women to access maternal health care services from the health facility. Observations suggest that involvement of CSG members created a favourable environment for effective group sessions within the community.

\section{Facility readiness and service quality}

The study team visited each HFWC at least once a month to observe the readiness of the facility and the quality of services provided. A total of 31 monitoring visits were made from January to June 2008. Findings indicate that service providers were present at the health facility during monitoring visits, whereas support staff at one facility was absent several times (Table 3). Cleanliness, client waiting space and sitting arrangements were also observed to be good and generally clean. Adequate BCC materials, especially posters, flipchart and pamphlets, were provided to HFWCs and posted. Facilities received Drugs and Dietary Supplement (DDS) kits regularly and sufficient quantities of contraceptive pills, condoms, injectables and IUDs were also available. Similarly, availability of infection prevention materials, including gloves, bleaching powder, burner, autoclave, cotton and antiseptic were available at the HFWCs, apart from a temporary shortage of autoclave and antiseptic at one HFWC. It was observed that, in all cases, providers maintained privacy with clients during the service provision.

\section{CSG meetings}

CSG members organized monthly meetings in a convenient time and place to know the status of intervention activities (Table 4). Some CSG members did not attend the meeting regularly and approximately 10-12 meetings out of 18 were held each month. The FWAs of each ward assisted the CSG members to organize the monthly meetings.
Table 3: Availability of services at HFWC (in percent)

\begin{tabular}{lcc}
\hline Issues & Bausha & Gaznaipur \\
Staff presence & NP & 86 \\
SACMO & 88 & 93 \\
FWV & 77 & 65 \\
Support staff & 100 & 86 \\
Cleanliness, waiting system and sitting arrangement \\
Waiting space clean & 100 & 100 \\
IUD insertion/Labor room clean & 100 & 100 \\
Providers room clean & 100 & 100 \\
Waiting system maintained properly & 100 & 100 \\
Adequate sitting arrangement & & \\
Availability of educational materials & & 100 \\
Posters on waiting room wall & 88 & 100 \\
Flipchart in provider's room & 100 & 93 \\
Pamphlet/Leaflet/Brochure & 100 & \\
Availability of infection prevention materials & \\
Gloves & 100 & 100 \\
Bleaching powder & 100 & 100 \\
Burner & 100 & 100 \\
Autoclave & 100 & 79 \\
Cotton & 100 & 100 \\
Antiseptic & 100 & 86 \\
Number of visits & 17 & 14 \\
\hline NP=Not Posted & & \\
\hline
\end{tabular}

\begin{tabular}{|lcc|}
\hline \multicolumn{3}{l}{ Table 4: Findings from CSG meetings at union (in percent) } \\
\hline Issues & Bausha & Gaznaipur \\
\cline { 2 - 3 } Category of members present & & \\
in meetings & 65 & 72 \\
Male UP member & 17 & 20 \\
Female UP member & 36 & 32 \\
School teacher & 26 & 63 \\
Religious leader & 94 & 98 \\
FWA & 23 & 6 \\
HA & 31 & 35 \\
Number of meetings observed & & \\
Information about meeting & 91 & 92 \\
Held on time & 65 & 75 \\
Held on schedule date & 100 & 98 \\
Meeting minutes discussed & 100 & 100 \\
Implementation status of the last & 100 & 100 \\
meeting activities discussed & 100 & 100 \\
Specific agenda for the meeting & 100 \\
Discussion held according to & 100 & 100 \\
agenda & 100 & 100 \\
Service related issues discussed & 100 \\
Meeting was participatory & 97 & 98 \\
Meeting minutes recorded by & 91 & 35 \\
FWA & & \\
Number of meetings observed & 31 & \\
\hline
\end{tabular}


A monitoring tool was designed to document the activities of the meeting. In most of the areas, male union parishad (UP) members played important roles in organizing meetings and female UP members, health assistants (HAs), teachers and religious leaders did not regularly attend the meetings. Meetings were held in a participatory manner and specific issues were discussed.

Workshops with CSG members were arranged primarily to share the experiences that the members gathered during the first six months of the interventions; a total of six workshops were organized. The participation of members at the workshop was satisfactory. The workshop participants identified problems and suggested possible solutions which have been highlighted below.

Problems identified: Staff shortages at the HFWCs and service providers' absenteeism are two unresolved problems. Moreover, fieldworkers are not providing the required information to voucher recipients about the process of using vouchers. Husbands of the voucher recipients are not generally informed about the importance of maternal health care services.

Solutions suggested: Fieldworkers need to be motivated to provide the required information to the voucher recipients. CSG members should emphasize the importance of monthly meetings as they identify problems and possible solutions. Selection of suitable meeting places may help to increase participation by community members and so FWAs should finalize monthly meeting dates in consultation with UP members for wider participation of community stakeholders. Husbands of voucher recipients need to be invited to the meetings and group sessions, which will serve as a platform to increase their awareness on maternal health care services. CSG members, who never attended monthly meetings, should be replaced by new members. One CSG member stated, "You bave educated us in such a way that we are now benefited. Now we know what we need to do for the poor pregnant women in your absence. We will support poor pregnant women in future and will organize monthly meetings regularly."

\section{FP committee meetings}

Union FP committees of Bausha and Gaznaipur unions were reactivated to identify implementation problems and possible solutions. At the beginning of the intervention, some of the members provided financial support to improve the physical conditions of health facilities. A monitoring checklist was developed to observe their monthly meetings. During the monitoring period, FP committee meetings were not held due to engagement of UP members, FWAs and FPIs in other national priorities, like preparing national voter list, updating couple registers by FWAs or any sudden activities assigned by their supervisors.

\section{Coordination committee members}

During monitoring visits to HFWCs and monthly meetings with voucher committee members, formal and informal discussions regarding the project activities were held with the government officials and service providers. For better coordination between the CSGs and service providers, as well as for smooth functioning of the project activities, the following recommendations were provided:

- Involvement of community stakeholders is necessary to select the poor pregnant women, as well as to identify problems and possible solutions in order to strengthen maternity care services. 
- Voucher recipients and their family members, especially husbands, need to be motivated in order to improve their knowledge on maternal health care services by the fieldworkers and CSGs.

- Active involvement of fieldworkers is needed to increase knowledge of maternal health care in the community. In addition, changing attitudes of service providers towards clients is crucial.

- Fieldworkers are identifying potential voucher recipients, filling the voucher registration forms and distributing voucher books among them. To sustain fieldworkers' interest in the voucher scheme, voucher registration fees could be introduced for the fieldworkers as an additional financial benefit.

- Free ultra-sonogram services for those who need it, and the allocation of medicines for normal delivery, need to be increased.

- Poor women, who have less than two children, should get priority in receiving voucher books as an effort to promote family planning.

\section{Number of poor pregnant women received vouchers}

Fieldworkers maintained a register to keep detailed information about the distribution of vouchers. Information collected by the study team showed that fieldworkers identified a total of 739 eligible pregnant women during the study period (Figure 2). Among these, a total of 702 women were validated as 'poor' by the CSG members. Since fieldworkers were instructed to prepare a list of poor pregnant women four months prior to introducing interventions, they created a list of poor pregnant women irrespective of their expected delivery date. However, voucher books were distributed only among those poor pregnant women who were expected to give birth during November 2007 to June 2008. Due to time considerations, therefore, 122 women were excluded from the voucher distribution list because

Figure 2: Number of pregnant women received vouchers

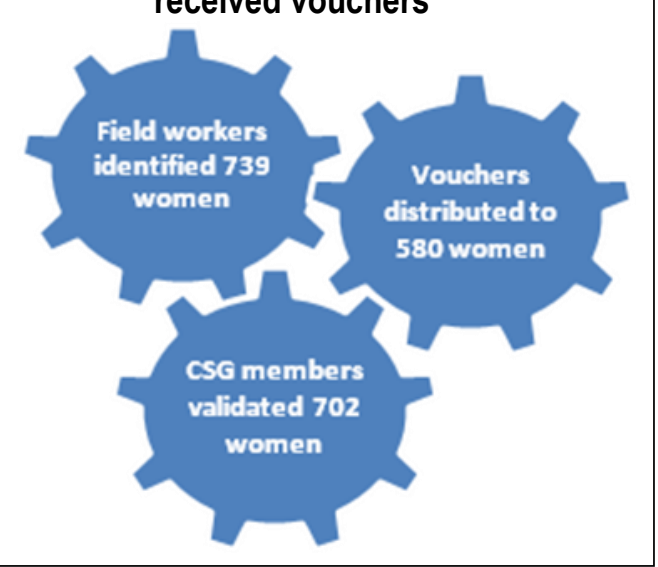
most of the deliveries occurred before the start of the interventions and few experienced a miscarriage or went to the parent's house for delivery. Thus 580 pregnant women received vouchers from the fieldworkers in both the unions covering 55 villages. 


\section{IMPACT EVALUATION}

\section{Fieldworkers' knowledge of maternal health care}

Fieldworkers' knowledge of the required number of ANC visits and the timing of those visits was fairly in both baseline and endline survey (79 percent vs. 93 percent). The most commonly reported danger signs at baseline were bleeding, convulsion and headache/blurred vision and 44 percent knew all five danger signs of pregnancy, which increased to 68 percent by the endline (see Table 5). For the three delays, at baseline most fieldworkers mentioned delay in reaching a health center and about half were aware of the other two delays. These proportions significantly increased by the endline, when 77 percent reported all three delays.

Table 5: Number of fieldworkers reported correct knowledge on maternal health care services

\begin{tabular}{|c|c|c|c|c|c|c|}
\hline \multirow{2}{*}{ Issues } & \multicolumn{2}{|c|}{ Bausha } & \multicolumn{2}{|c|}{ Gaznaipur } & \multicolumn{2}{|c|}{ Total } \\
\hline & Baseline & Endline & Baseline & Endline & Baseline & Endline \\
\hline \multicolumn{7}{|l|}{ Five danger signs } \\
\hline Bleeding & 11 & 10 & 7 & 7 & 18 & 19 \\
\hline Convulsion & 7 & 11 & 9 & 9 & 16 & 22 \\
\hline Headache /Blurred vision & 7 & 8 & 7 & 11 & 14 & 19 \\
\hline High fever & 5 & 8 & 5 & 8 & 10 & 16 \\
\hline Prolonged labor & 5 & 10 & 5 & 11 & 10 & 21 \\
\hline \multicolumn{7}{|l|}{ Three delays } \\
\hline Delay in decision making & 7 & 10 & 3 & 11 & 10 & 21 \\
\hline Delay to reach health facility & 8 & 11 & 9 & 11 & 17 & 22 \\
\hline Delay in receiving services & 9 & 8 & 2 & 10 & 11 & 18 \\
\hline 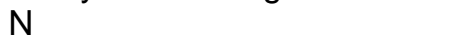 & 11 & 11 & 12 & 11 & 23 & 22 \\
\hline
\end{tabular}

Knowledge of the TT schedule and requirements for immunization was universal among the fieldworkers (Figure 3). Correct knowledge of the duration of effectiveness of a TT injection increased slightly, but remained quite poor. Most fieldworkers had correct knowledge about the timing of PNC visits and taking a Vitamin A capsule. Most fieldworkers already had correct knowledge about the duration of exclusive breastfeeding and this increased to 100 percent after the training.

Figure 3: Correct knowledge on maternal health care issues by the fieldworkers (in percent)

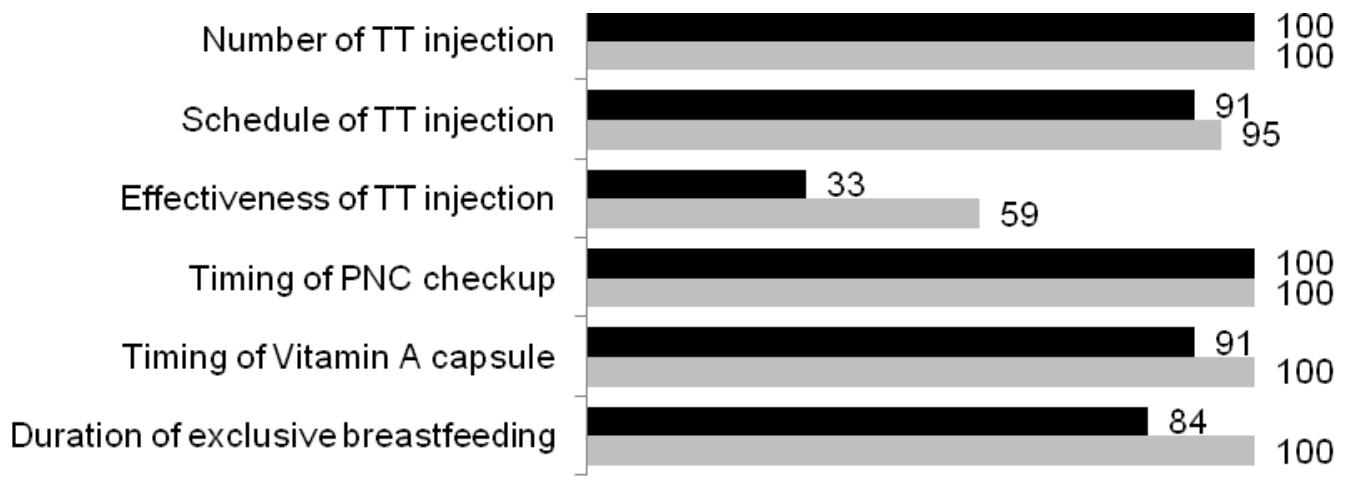

Baseline Endline 


\section{Characteristics of the women interviewed}

A comparison of the characteristics of the women interviewed at baseline and at endline showed no significant differences in terms of their age and the occupations of the women and their husbands (see Table 6). The difference in mean age between women and their husband was about 10 years. The educational level of women and their husbands was slightly higher during endline compared to the baseline, which may suggest that women using the vouchers may be more educated. The majority of women were housewives and their husbands were primarily farmers, daily labourers and small business vendors.

Table 6: Background characteristics of women and husbands (in percent)

\begin{tabular}{|c|c|c|c|c|c|c|}
\hline \multirow{2}{*}{ Characteristics } & \multicolumn{2}{|c|}{ Bausha } & \multicolumn{2}{|c|}{ Gaznaipur } & \multicolumn{2}{|c|}{ Total } \\
\hline & Baseline & Endline & Baseline & Endline & Baseline & Endline \\
\hline \multicolumn{7}{|l|}{ Age of women (years) } \\
\hline$<25$ & 44.6 & 42.1 & 43.9 & 36.2 & 44.2 & 39.6 \\
\hline $25-29$ & 29.5 & 26.7 & 26.4 & 30.4 & 28.0 & 28.3 \\
\hline $30-34$ & 17.7 & 15.6 & 18.1 & 24.0 & 17.9 & 19.1 \\
\hline$>35$ & 8.2 & 15.6 & 11.6 & 9.4 & 9.9 & 13.0 \\
\hline Total & 100.0 & 100.0 & 100.0 & 100.0 & 100.0 & 100.0 \\
\hline Mean & 26.0 & 27 & 27 & 27 & 26 & 27 \\
\hline SD & 5.9 & 6.1 & 6.2 & 6.2 & 6.1 & 6.2 \\
\hline \multicolumn{7}{|l|}{ Husband's age (years) } \\
\hline Mean & 37 & 35 & 37 & 36 & 37 & 36 \\
\hline $\begin{array}{l}\text { SD } \\
\text { Years of schooling (wo }\end{array}$ & \multicolumn{5}{|c|}{ Years of schooling (women) } & 8.2 \\
\hline Illiterate & 66.3 & 49.0 & 69.9 & 49.1 & 68.1 & 49.0 \\
\hline Incomplete primary & 19.1 & 19.7 & 18.5 & 23.4 & 18.8 & 21.3 \\
\hline Completed primary & 10.5 & 16.5 & 9.3 & 19.3 & 9.9 & 17.6 \\
\hline Higher than primary & 4.1 & 14.8 & 2.3 & 8.2 & 3.2 & 12.1 \\
\hline Total & 100.0 & 100.0 & 100.0 & 100.0 & 100.0 & 100.0 \\
\hline \multicolumn{7}{|c|}{ Years of schooling (husband) } \\
\hline Illiterate & 71.8 & 58.8 & 75 & 53.8 & 74.1 & 57.7 \\
\hline Incomplete primary & 15.5 & 19.8 & 11.6 & 18.1 & 12.9 & 18.5 \\
\hline Completed primary & 8.2 & 11.9 & 11.1 & 17.6 & 9.6 & 13.9 \\
\hline Higher than primary & 4.5 & 9.5 & 2.3 & 10.5 & 3.4 & 9.9 \\
\hline Total & 100.0 & 100.0 & 100.0 & 100.0 & 100.0 & 100.0 \\
\hline \multicolumn{7}{|l|}{ Occupation of women } \\
\hline Housewife & 95.6 & 97.1 & 94.4 & 98.8 & 95.2 & 97.8 \\
\hline Others & 4.1 & 2.8 & 5.6 & 1.2 & 4.8 & 2.3 \\
\hline \multicolumn{7}{|l|}{ Husband's occupation } \\
\hline Small business & 15.8 & 12.7 & 11.3 & 8.8 & 13.6 & 11.1 \\
\hline Skilled labour/Service & 8.9 & 3.7 & 4.7 & 3.6 & 6.8 & 3.6 \\
\hline Farmer/Agriculture labor & 36.7 & 25.1 & 30.1 & 32.2 & 33.6 & 28.1 \\
\hline Day labor & 19.5 & 31.3 & 20.8 & 40.1 & 20.1 & 35.0 \\
\hline Transport workers & 4.2 & 9.9 & 12.3 & 7.6 & 8.2 & 9.0 \\
\hline Fisherman & 9.8 & 14.0 & 14.2 & 4.1 & 11.9 & 9.9 \\
\hline Others & 5.1 & 3.3 & 6.6 & 3.6 & 5.8 & 3.3 \\
\hline Total & 100.0 & 100.0 & 100.0 & 100.0 & 100.0 & 100.0 \\
\hline $\mathrm{N}$ & 220 & 243 & 216 & 171 & 436 & 414 \\
\hline
\end{tabular}

A comparison of the demographic characteristics of the women (see Table 7) revealed that, for all indicators, there was no significant difference. The average number of living children was three and 
one-quarter of respondents had ever experienced a miscarriage, stillbirth, abortion or had menstrual regulation. The proportion of women reporting a stillbirth was relatively low during the baseline compared to endline ( 1 percent vs. 3 percent) because the selection criteria were for women who had a living child of less than one year at the time of the survey.

Table 7: Demographic characteristics of women (in percent)

\begin{tabular}{lcccccc}
\hline \multirow{2}{*}{ Characteristics } & \multicolumn{2}{c}{ Bausha } & \multicolumn{2}{c}{ Gaznaipur } & \multicolumn{2}{c}{ Total } \\
\cline { 2 - 7 } & Baseline & Endline & Baseline & Endline & Baseline & Endline \\
\hline Number of living children & & & & & & \\
$0-1$ & 17.3 & 30.4 & 17.6 & 22.9 & 17.4 & 27.3 \\
2 & 22.7 & 20.2 & 21.8 & 19.9 & 22.2 & 20.0 \\
3 & 20.5 & 19.8 & 20.8 & 20.5 & 20.6 & 20.0 \\
$4+$ & 39.5 & 29.6 & 39.8 & 36.7 & 39.8 & 32.7 \\
Mean & 3.2 & 3.0 & 3.2 & 3.1 & 3.2 & 3.0 \\
Ever experienced miscarriage/abortion/stillbirth/MR & & & & \\
Yes & 31.8 & 26.7 & 19.9 & 22.8 & 25.9 & 25.1 \\
No & 68.2 & 73.3 & 80.1 & 77.2 & 74.1 & 74.9 \\
Outcome of last pregnancy & & & & & & \\
Live birth & 98.2 & 96.3 & 99.5 & 98.2 & 98.9 & 97.1 \\
Still birth & 1.8 & 3.7 & 0.5 & 1.8 & 1.1 & 2.9 \\
N & 103 & 58 & 66 & 36 & 169 & 94 \\
\hline
\end{tabular}

\section{Effect on women's knowledge}

Life-threatening maternal conditions: Overall, women's awareness of potentially life-threatening complications during pregnancy, delivery and the postpartum period was significantly higher among those interviewed at the endline survey (Table 8). The majority of the women $(90 \%)$ at baseline were able to report at least one life-threatening complication and 28 percent could name at least three and these increased to 93 and 37 percent respectively at endline.

Table 8: Women's perceptions of life-threatening complications

\begin{tabular}{lcccccc}
\hline \multirow{2}{*}{ Major complications } & \multicolumn{2}{c}{ During pregnancy (\%) } & \multicolumn{2}{c}{ Delivery (\%) } & \multicolumn{2}{c}{ Postpartum (\%) } \\
\cline { 2 - 7 } & Baseline & Endline & Baseline & Endline & Baseline & Endline \\
\hline Severe headache/Blurry vision & 9.1 & 14.7 & 5.2 & 12.3 & 6.4 & 13.5 \\
High blood pressure & 6.7 & 11.6 & 3.2 & 11.4 & 4.1 & 15.2 \\
Convulsion/Eclampsia & 64.0 & 73.4 & 40.8 & 64.3 & 40.6 & 52.9 \\
Excessive vaginal bleeding & 8.7 & 4.1 & 8.0 & 8.0 & 14.4 & 16.1 \\
Tetanus & 36.2 & 39.1 & 21.3 & 25.6 & na & na \\
Baby's hand or feet come first & na & na & 22.2 & 52.9 & na & na \\
Prolonged labor & na & na & 16.1 & 19.7 & na & na \\
Obstructed labor & na & na & 36.9 & 39.9 & na & na \\
Retained placenta & na & na & 22.5 & 26.3 & na & na \\
Torned uterus & na & na & 7.6 & 11.3 & na & na \\
N & 220 & 243 & 216 & 171 & 436 & 414 \\
\hline
\end{tabular}

${ }^{*}$ Multiple responses; na $=$ not applicable 
Sources for treatment of life-threatening complications: Most women identified a qualified doctor as the source for treatment on life-threatening complications (Figure 4). The proportion mentioning other qualified medical staff increased significantly between surveys. However, endline findings also show that about one-quarter of the women reported unqualified providers as a source for treatment, although this may be due to respondents providing multiple responses.

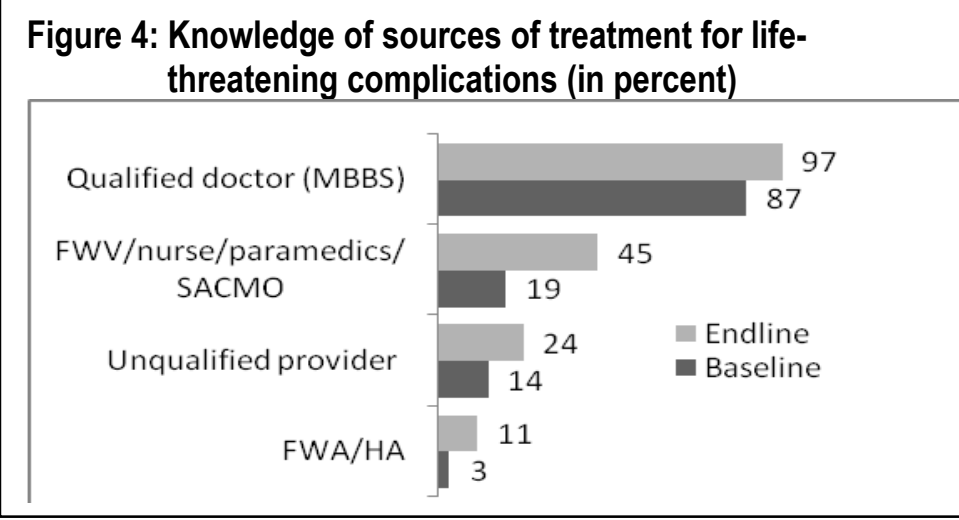

Places for a safe delivery: Respondents were asked to identify the place of safe delivery (Figure 5). The majority of women reported a Union Health Center and District hospital as the best places for a safe delivery, and the proportions reporting this increased at the endline. The perception of an HFWC as a safe place also increased significantly. The proportion of women mentioning a UHC was higher at endline because the voucher scheme mostly focused on strengthening the UHC for delivery

Figure 5: Knowledge of sources of safe delivery (in percent)

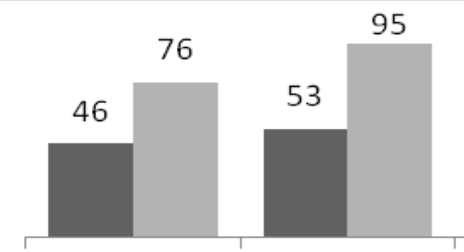

District hospital

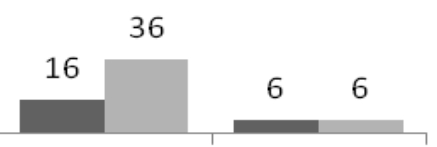

MBBS doctor/private hospital care because the providers do not stay at HFWC and district hospitals are distant from the union.

Vitamin A capsule and breastfeeding: Regarding knowledge on the intake of vitamin A capsule, 37 percent of the women during baseline survey correctly knew that it should be taken within 14 days after delivery; and this figure has significantly increased to 52 percent due to intervention. Similarly, knowledge on the duration of exclusive breastfeeding for 6 months also significantly increased from 45 to 61 percent.

\section{Utilization of ANC services}

At baseline, 79 percent of women received $\mathrm{ANC}$ and this increased to 89 percent at endline, although 85 percent of women received the voucher books at 6 - 9 months of pregnancy and so this may underestimate the number accessing ANC at endline (Figure 6). Among those whose visit was due during the intervention period, the proportions having at least three visits increased dramatically.

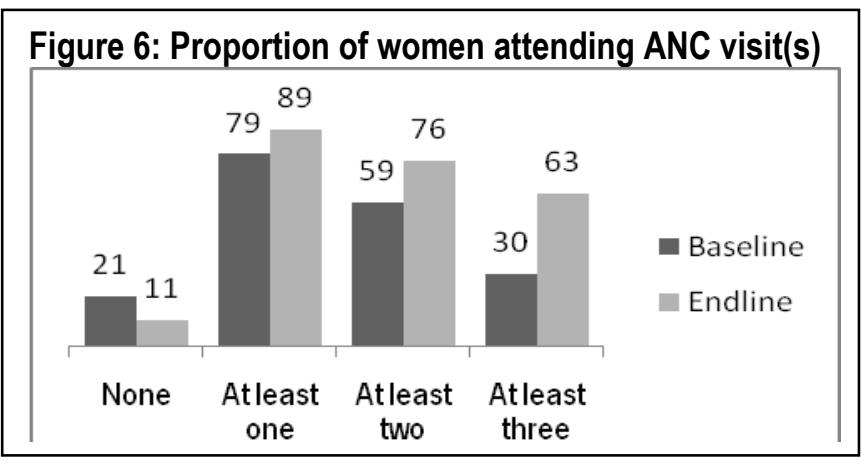


Providers consulted for ANC services: When asked which types of providers they consulted for ANC services, there were substantial changes between the baseline and endline (see Table 9); among women interviewed at endline, all of them reported consulting at least one trained provider whereas only one half of the women interviewed at baseline had done so. FWV's (97 percent) were by far the most consulted provider. In the absence of a FWV, a SACMO provided services at the union-level health facilities and only few women of Gaznaipur union received services from male provider (SACMO).

Table 9: Providers consulted for ANC services (in percent)

\begin{tabular}{lcccccc}
\hline \multirow{2}{*}{ Providers $^{*}$} & \multicolumn{2}{c}{ Bausha } & \multicolumn{2}{c}{ Gaznaipur } & \multicolumn{2}{c}{ Total } \\
\cline { 2 - 7 } & Baseline & Endline & Baseline & Endline & Baseline & Endline \\
\hline Qualified doctor (MBBS) & 20.0 & 0.0 & 33.9 & 0.0 & 27.3 & 0.0 \\
Nurse/Paramedic & 7.3 & 0.9 & 0.6 & 0.0 & 3.8 & 0.6 \\
FWV & 14.0 & 99.5 & 28.9 & 92.8 & 21.7 & 96.7 \\
SACMO & 3.6 & 0.0 & 1.7 & 15.9 & 2.7 & 6.5 \\
FWA & 35.2 & 0.0 & 29.4 & 0.0 & 32.2 & 0.0 \\
Others & 35.2 & 0.0 & 33.9 & 0.0 & 34.5 & 0.0 \\
At least one qualified provider & 40.1 & 100.0 & 65.1 & 100.0 & 53.6 & 100.0 \\
N & 165 & 218 & 180 & 151 & 345 & 369 \\
\hline
\end{tabular}

*Multiple responses

Services provided during ANC consultations: Pregnant women could receive physical and laboratory tests during ANC using the vouchers in the book. As can be seen in Table 10, provision of these vouchers dramatically increased the number and type of services received by the women during ANC consultations.

Table 10: Services/examinations provided during ANC check-up (in percent)

\begin{tabular}{lcccccc}
\hline \multirow{2}{*}{ Services/examinations } & \multicolumn{2}{c}{ Bausha } & \multicolumn{2}{c}{ Gaznaipur } & \multicolumn{2}{c}{ Total } \\
\cline { 2 - 7 } & Baseline & Endline & Baseline & Endline & Baseline & Endline \\
\hline Weight measure & 32.7 & 99.1 & 18.3 & 97.4 & 25.2 & 98.4 \\
Height measure & 13.3 & 73.9 & 3.3 & 94.7 & 8.1 & 82.4 \\
BP measure & 48.5 & 92.2 & 50.0 & 94.0 & 49.3 & 93.0 \\
Blood test & 11.5 & 67.4 & 7.2 & 89.4 & 9.3 & 76.4 \\
Urine test & 15.8 & 90.4 & 11.1 & 93.4 & 13.3 & 91.6 \\
Abdomen examination & 59.4 & 96.3 & 44.4 & 94.7 & 51.6 & 95.7 \\
Eye examination & 47.9 & 78.9 & 47.2 & 66.9 & 47.5 & 74.0 \\
$\mathrm{~N}$ & 165 & 218 & 180 & 151 & 345 & 369 \\
\hline
\end{tabular}

During the baseline, 21 percent of women did not seek any ANC services at all. The most frequently cited reasons were lack of money (71 percent) followed by perceived lack of need (31 percent) and familial constraints ( 3 percent). Among the women with vouchers who did not use them, about half reported not having an opportunity because they received the voucher book when nine months pregnant. Among the remaining six percent, their reasons included unavailability of service providers at health facility, facility closed at time of visit, long waiting times, husband/family members preventing visit, and perceived unpleasant behavior of providers. 


\section{Quality of care during last ANC visit}

The voucher book was designed to record the results of the physical and medical examinations to help identify pregnancies that are at risk. Examination and recordkeeping during the first ANC visit lasted about 25 minutes. About three-quarters of women reported being treated in a friendly manner at baseline, which significantly increased to 96 percent at endline (Table 11). Information about where to go for pregnancy-related complications also increased significantly, as did the proportion of women requested to make a follow-up visit. Use of educational materials increased tremendously, although the proportion remained low at less than one third. The proportion of women claiming that service providers delayed providing services significantly reduced after introduction of the vouchers.

Table 11: Quality of care addressed during last ANC visit (in percent)

\begin{tabular}{lcccccc}
\hline \multirow{2}{*}{ Quality of care issues } & \multicolumn{2}{c}{ Bausha } & \multicolumn{2}{c}{ Gaznaipur } & \multicolumn{3}{c}{ Total } \\
\cline { 2 - 7 } & Baseline & Endline & Baseline & Endline & Baseline & Endline \\
\hline Treated in friendly manner & 67.7 & 95.0 & 82.9 & 96.7 & 75.3 & 95.7 \\
Informed where to visit for & 32.1 & 91.6 & 14.8 & 93.4 & 23.1 & 92.3 \\
pregnancy-related complications & 53.6 & 90.7 & 45.1 & 87.5 & 49.1 & 89.4 \\
$\begin{array}{l}\text { Requested for follow up visits } \\
\text { Educational materials used for }\end{array}$ & 4.2 & 32.3 & 2.2 & 30.3 & 3.1 & 31.5 \\
$\begin{array}{l}\text { counselling } \\
\text { Provided leaflet on maternal health }\end{array}$ & na & 33.6 & na & 41.4 & na & 36.8 \\
care issues & 44.1 & 6.9 & 14.4 & 4.0 & 29.4 & 5.7 \\
$\begin{array}{l}\text { Delayed to provide services } \\
\mathrm{N}\end{array}$ & 165 & 218 & 180 & 151 & 345 & 369 \\
\hline
\end{tabular}

na $=$ not applicable

\section{Assistance during delivery}

Table 12 shows the type of person who provided assistance during the woman's last delivery (in some cases, more than one person assisted at delivery). At baseline, only 5.5 percent of deliveries were assisted by a trained provider including a doctor (MBBS), nurse, paramedic, FWV or SBA. This proportion increased substantially and significantly to 22 percent at endline, most probably because of the financial support provided to poor pregnant women through the vouchers.

Table 12: Persons assisting during delivery (in percent)

\begin{tabular}{lcccccc}
\hline \multirow{2}{*}{ Persons } & \multicolumn{2}{c}{ Bausha } & \multicolumn{2}{c}{ Gaznaipur } & \multicolumn{2}{c}{ Total } \\
\cline { 2 - 7 } & Baseline & Endline & Baseline & Endline & Baseline & Endline \\
\hline Trained providers & 6.9 & 26.8 & 4.2 & 14.1 & 5.5 & 21.6 \\
TBA & 81.4 & 70.0 & 84.7 & 78.4 & 83.0 & 73.4 \\
Untrained providers & 11.8 & 3.3 & 11.1 & 7.5 & 11.5 & 5.0 \\
$\mathrm{~N}$ & 220 & 243 & 216 & 171 & 436 & 414 \\
\hline
\end{tabular}




\section{Place of delivery}

Table 13 describes the place of delivery reported for all live births and stillbirths during the last pregnancy. At baseline, home deliveries were almost universal but this proportion decreased significantly over the intervention period, with an accompanying increase in institutional deliveries. The proportion of institutional deliveries still remained low in Gaznaipur union because of the availability and active participation of SBA to perform normal deliveries in that area. Deliveries mostly took place at the UHC (12 percent) and district hospital (5 percent); only one percent of women received delivery care from other designated health facilities within the voucher scheme, including the HFWC, MCWC, NGO facility and private facilities.

Table 13: Place of last delivery (in percent)

\begin{tabular}{lrrrrrr}
\hline \multirow{2}{*}{ Places } & \multicolumn{2}{c}{ Bausha } & \multicolumn{2}{c}{ Gaznaipur } & \multicolumn{2}{c}{ Total } \\
\cline { 2 - 7 } & Baseline & Endline & Baseline & Endline & Baseline & Endline \\
\hline Home & 97.7 & 73.3 & 97.7 & 93.6 & 97.7 & 81.7 \\
At own home & 84.5 & 68.8 & 88 & 86 & 86.2 & 75.8 \\
Parent's home & 13.2 & 4.5 & 9.7 & 7.6 & 11.5 & 5.9 \\
Health facility & 2.4 & 26.7 & 2.4 & 6.4 & 2.3 & 18.3 \\
District hospital & 1.4 & 7.4 & 0.0 & 2.3 & 0.7 & 5.3 \\
UHC & 0.0 & 18.5 & 1.9 & 2.3 & 0.9 & 11.9 \\
Others & 1.0 & 0.8 & 0.5 & 1.8 & 0.7 & 1.1 \\
N & 220 & 243 & 216 & 171 & 436 & 414 \\
\hline
\end{tabular}

Reasons for not delivering at a health facility: Despite having the financial support of the voucher book, the majority of women did not deliver at a designated health facility. It was mostly the respondents themselves who decided not to deliver at health facility, although in 12 percent of cases it was the parents or in-laws and in eight percent the husband. Baseline findings had revealed that, among the women who delivered at home, the most frequently cited reason was the monetary constraint (72 percent) on delivering at a facility, followed by a perceived absence of need to deliver at an institution (28 percent) as a preference for delivering at home because of the care available (21 percent).

The reasons given at endline for not delivering at a health facility among women having a voucher book were: i) did not have any problems and so didn't perceive the need (60 percent); ii) labour pain started suddenly ( 25 percent); iii) had no-one to accompany them to the health facility (14 percent); iv) a fear of the facility (12 percent). Seventeen percent of the women also raised issues about the perceived poor quality of service, unpleasant behavior of providers, long waiting times and unsuitable service hours.

\section{Complications experienced}

Table 14 shows the types of life-threatening maternal complications that women reported experiencing during their last pregnancy. Over all three phases, there were tremendous reductions in the proportions of women reporting experience of one or more complications, especially during pregnancy. Among the women who received voucher books, 90 percent consulted a providers during their pregnancy, which confirms that when women consult with a trained provider it provides an opportunity to improve their level of understanding of maternal health care issues, as well as reducing their chances of experiencing complications. 
Table 14: Women's experiences of life-threatening complications during pregnancy, delivery and postpartum

\begin{tabular}{lcccccc}
\hline \multirow{2}{*}{ Complications* } & \multicolumn{2}{c}{ During pregnancy (\%) } & \multicolumn{2}{c}{ Delivery (\%) } & \multicolumn{2}{c}{ Postpartum (\%) } \\
\cline { 2 - 7 } & Baseline & Endline & Baseline & Endline & Baseline & Endline \\
\hline No complications & 26.8 & 75.4 & 40.8 & 75.4 & 43.8 & 69.8 \\
One or more complications & 73.2 & 24.6 & 59.2 & 24.6 & 56.2 & 30.2 \\
Severe headache/Blurry vision & 31.1 & 6.1 & 25.0 & 1.7 & 15.1 & 9.2 \\
High blood pressure & 16.7 & 1.4 & 12.8 & 2.9 & 6.7 & 2.2 \\
Convulsion/Eclampsia & 20.0 & 2.9 & 5.0 & 2.2 & 3.0 & 1.9 \\
Excessive vaginal bleeding & 4.4 & 0.5 & 14.4 & 0.2 & 7.6 & 4.6 \\
Abdominal pain & 7.6 & 9.4 & na & na & 8.0 & 8.7 \\
Baby's hand or feet come first & na & na & 2.3 & 1.7 & na & na \\
Prolonged labor & na & na & 28.9 & 11.4 & na & na \\
Obstructed labor & na & na & 6.7 & 1.7 & na & na \\
Retained placenta & na & na & 7.6 & 1.2 & na & na \\
Torned uterus & na & na & 2.5 & 1.0 & na & na \\
Others & 9.3 & 7.3 & 3.1 & 3.2 & 7.7 & 8.5 \\
N & 220 & 243 & 216 & 171 & 436 & 414 \\
\hline
\end{tabular}

*Multiple responses; na $=$ not applicable

Treatment-seeking behavior for maternal complications: Those respondents who reported experiencing at least one complication during pregnancy, delivery or postpartum were asked whether they consulted a qualified providers about the complication. Irrespective of the type of complications, about two-thirds of women reported visiting a qualified provider (see Figure 7). The proportion of women receiving treatment from a trained provider has increased substantially following introduction of financial support through the voucher book, regardless of the type of complications.

\section{Figure 7: Proportion of women experiencing a complication who consulted with a trained} provider (in percent)

\section{Endline Baseline}

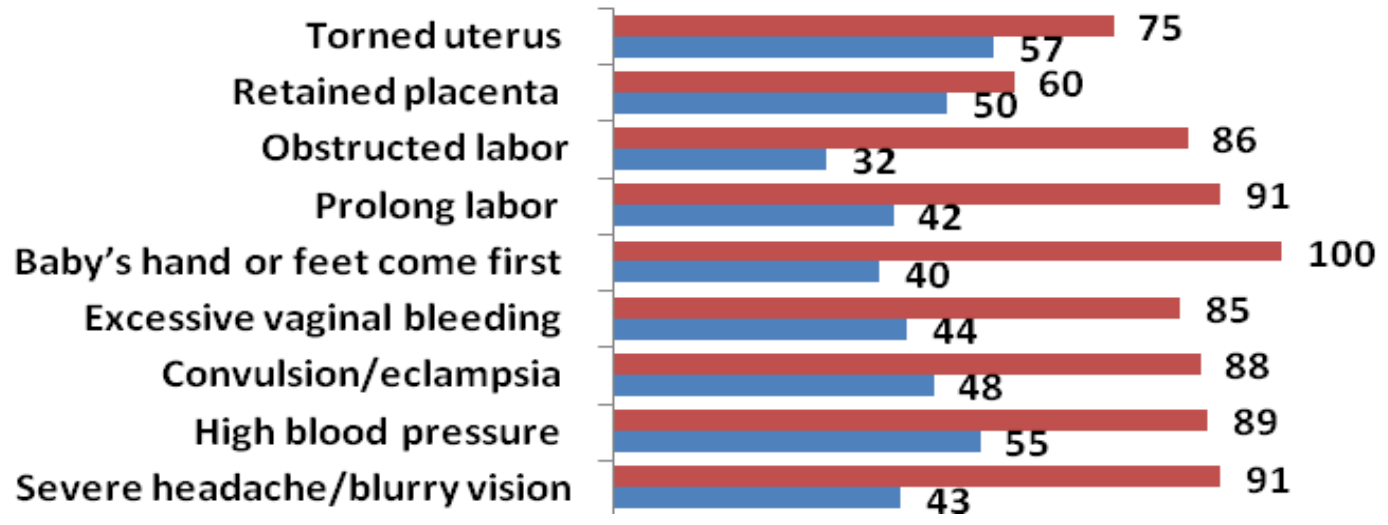


Among women who did not experience any life-threatening complications, only 15 percent received delivery care from a trained provider (8\% from doctors and $7 \%$ from paramedics). Among women who experienced a life-threatening complication, sixty percent delivered their baby with assistance from a trained provider (34\% from doctors and 24\% from paramedics), but this means that forty percent of complicated deliveries were assisted by untrained providers. Although this is still a major challenge, it is a positive indication of the immediate effect of introducing the voucher scheme on access to critical services.

\section{Utilization of PNC services}

Respondents were asked whether they went for a check-up, either for themselves or for their baby, during the 42 days following delivery and, if so, what types of providers were seen and facility visited. Those who did not go for a check-up were asked their reasons for not doing so.

Only 45 percent of women reported having a postnatal check-up for themselves during baseline and this increased significantly to 60 percent after introduction of the interventions (see Table 15). Before the interventions, 22 percent of respondents received PNC check-up from a trained provider, which increased to 100 percent afterwards. Most mothers received their postnatal checkup within two weeks following delivery. Baseline findings showed that 44 percent of respondents received PNC at home, 41 percent visited an untrained provider/pharmacy and 15 percent visited a health facility. After the intervention, all respondents accessing PNC services did so at a health facility.

Table 15: Utilization of PNC check-up (in percent)

\begin{tabular}{lcccccc}
\hline \multirow{2}{*}{ Issues } & \multicolumn{2}{c}{ Bausha } & \multicolumn{2}{c}{ Gaznaipur } & \multicolumn{2}{c}{ Total } \\
\cline { 2 - 7 } & Baseline & Endline & Baseline & Endline & Baseline & Endline \\
\hline Proportion of women received PNC & 39.1 & 64.2 & 51.4 & 54.4 & 45.2 & 60.1 \\
$\mathrm{~N}$ & 220 & 243 & 216 & 171 & 436 & 414 \\
Person consulted for PNC & & & & & & \\
Doctors & 10.5 & 0.0 & 25.2 & 0.0 & 18.8 & 0.0 \\
FWV/Nurse/Paramedics & 3.5 & 100.0 & 0.0 & 95.7 & 1.5 & 98.4 \\
SACMO & 4.7 & 0.0 & 0.0 & 4.3 & 2.0 & 1.6 \\
Untrained providers & 81.4 & 0.0 & 74.8 & 0.0 & 77.8 & 0.0 \\
$\mathrm{~N}$ & 86 & 156 & 111 & 93 & 197 & 249 \\
Visiting place for PNC & & & & & & \\
Home & 46.5 & 0.0 & 42.3 & 0.0 & 44.2 & 0.0 \\
Hospital/UHC & 9.3 & 30.1 & 16.2 & 1.1 & 13.2 & 19.2 \\
HFWC & 3.5 & 69.9 & 1.0 & 98.9 & 2.0 & 80.8 \\
Traditional providers/Pharmacy & 40.7 & 0.0 & 40.5 & 0.0 & 40.6 & 0.0 \\
$\mathrm{~N}$ & 86 & 156 & 111 & 93 & 197 & 249 \\
\hline
\end{tabular}

Among those who did not seek postnatal care, at baseline the primary reasons were lack of money $(71 \%)$ and the perceived absence of need (31\%). At endline, the reasons included women not knowing that the voucher could be used for PNC (24\%), providers not provide services when the woman visited the facility (23\%), not experiencing any problem (17\%), fear about services (15\%) and service related problems $(17 \%)$, i.e., poor quality of service, transportation problem, reluctance to see male providers, etc. 


\section{Utilization of transport and medicine vouchers}

Among those who used vouchers for maternal health care services, 99 percent indicated that they did not face any problems in utilizing the transport and medicine vouchers. All women received a stipulated amount for the transport services and all women indicated that they received medicines in exchange for the vouchers and did not experience any problems. However, most of the women also stated that they had to spend additional money to purchase medicines for a normal delivery.

\section{Women's perceptions of the services and vouchers}

To collect detailed information about the mechanism and problems for utilizing vouchers, in-depth interviews were conducted with 15 women who had used maximum number of vouchers and with 15 women who did not use any of the vouchers. Women were interviewed at their home using a detailed guideline and interviews were tape recorded to avoid loss of information. All in-depth interviews were transcribed immediately afterwards to ensure the quality of information.

The mean age of respondents was 26 years. The majority (90 percent) was Muslims and 43 percent were illiterate. Most were housewives, apart from three women who were tailors. The mean age of husbands was 35 years and 40 percent were illiterate; their occupations varied, including farmer, rickshaw puller, potter, day labor, fisherman, carpenter, mason, and small business. The average number of children was 2.6; the average number of family members was seven and most lived in a joint family.

Knowledge on voucher scheme: Most women learned about the voucher activities from an FWA, although other sources included UP members, CSG members and HAs. About half (54\%) received the voucher book within the first six months of their pregnancy and in most of the cases the FWAs distributed the voucher books during routine household visits; in a few cases, women collected the voucher book from the FWA's residence. Women reported that they did not face any difficulties in obtaining the voucher book. The majority of the women could not name all types of vouchers in the book, but could mention the places providing the services.

Utilization of ANC services: Most women visited an HFWC for ANC and PNC services; a few who resided near the UHC received services there. The majority of women reported that they themselves decided to receive ANC services from the health facility; about half were accompanied by either parents/parents-in-laws or CSG members.

All voucher recipients reported not facing any problems while receiving ANC services. They stated that the service providers treated them well, although four women reported waiting a long time due to the high client load. Most women used a rickshaw/van to reach the health facility, with some using a taxi, bus or on foot. The women did not face any problems using the transport voucher for renting vehicles or for receiving the transport allowance from service providers.

Utilization of delivery care services: Of the 15 deliveries, 11 were at the UHC, three at district hospital and one at HFWC. Two required caesarean intervention. In all cases, the couple jointly decided to receive delivery care services from the health facility and all women were accompanied by either their husband or other family members. Two women mentioned unpleasant behavior by nurses during delivery care. Only two women reported that they had to wait a long time for services. 
All women used the transport voucher when seeking delivery care at a health facility. Most used the three-wheeler vehicles and all received the stipulated transport allowance; none reported facing any problems renting a vehicle or receiving the allowance. Three women were referred to a district hospital and did not experience any problems in receiving services or the transport allowance.

Women used the voucher to purchase medicines from the selected commercial drug stores and only one woman faced a problem, as the medicines were not available at the HFWC. There was no provision for purchasing medicines through the voucher at the union level. Most women spent additional money for delivery care, by selling property or taking loans.

Management of complications: Among the 15 women, five reported having complications during pregnancy, one during delivery, and one during the postnatal period. All women who experienced complications received services in exchange of voucher with no problems reported, and visited either the UHC or district hospital.

Utilization of PNC services: Among the 15 women, 11 received PNC care from the FWV or SACMO; nine received care from the union level HFWCs and two from upazila level health facilities. Five women went alone and the others were accompanied by relatives, mostly mother-inlaw. One woman reported that the service provider did not examine her properly and five reported having to wait a long time to receive the PNC services. Most women used a rickshaw/van to reach the health facility and all women reported receiving the specified transport allowance. The four women who did not access PNC services reported unavailability of the service or poor quality of service as the reasons.

Voucher related issues: A question was asked to know the future intention of voucher recipients' to visit health facility if financial support was withdrawn. Approximately, two-thirds of the women showed interest to receive more services from the health facility and all the respondents wanted to receive delivery care from the facility. Six respondents cited financial difficulties related to transport and medicines during ANC, delivery and PNC. One voucher user in Gaznaipur union said, "As I have received services using the voucher book, I will seek services in future even if I don't have the voucher book. I will seek services even if I don't get the transportation allowance." The voucher users were asked whether they felt stigmatized because the vouchers were intended for the poorest of the poor; the respondents reported that they did not feel any discrimination.

The following suggestions for improving the scheme were given by the respondents:

- Increase the amount of the medicine voucher to cover the full cost of medicines and/or provide the required medicines at each health facility.

- Increase transport costs for those who have to travel a long distance.

- Perform ultra sonogram free of cost.

- Ensure availability of caesarean delivery at the upazila level health facility.

- Ensure pleasant and friendly behavior from service providers.

One voucher user of Gaznaipur union said "I have had a good experience with this and have benefited. This scheme provided me free maternity services and allowances for transportation and medicines. I did not spend any money during the delivery. I received services by using the voucher book." 
Non-use of vouchers: About 10 percent of voucher recipients did not utilize vouchers for maternal health care services. In-depth interviews with non-users indicated the following reasons for not using the vouchers for ANC:

- Received voucher book at later stage of pregnancy

- Health facility was closed

- Service providers were not available at the facility

- Women visited the health facility but could not access the service because of long queues

- Fieldworkers did not inform them properly about how to use it.

One voucher recipient in Gaznaipur union said, "The FWA of our locality did not inform me how to use the voucher book. I did not know that she (FWA) had listed my name as one of the poor. She just called me to her home and gave me the book and did not provide any information regarding it. So, I did not use it."

The reasons given for not accessing delivery care from a health facility included:

- Were not informed that delivery care could be accessed in exchange for a voucher

- Did not feel the need for this service

- Labor pain started suddenly, often at night, and there was no opportunity to visit the facility

- Family members were not available to accompany the women to the health facility

- Previous experience (e.g. unavailability of service provider/health facility closed) discouraged her from visiting the facility

- Traditional birth attendant (dai) was more convenient and performed the delivery at home

- Stayed at parent's house during delivery

- Guessed that the service provider might delay treatment and not provide medicine.

Similar comments were made concerning PNC services. Half of the women had not been informed about that they could access PNC services using the voucher book. Others reported not perceiving a need for the service, anticipating a delay in treatment by the service provider, and having to wait a long time at the facility.

\section{COST OF SERVICES}

One important component of the study was the maintenance of rigorous financial records to be able to determine the cost per service delivered through this scheme. Population Council and RTM International jointly developed guidelines for the service providers to address their reimbursement under this scheme. According to the guidelines, a certain portion of the funds allocated for consultation fees should remain as a seed fund that can be used to ensure smooth implementation of the project, i.e. for purchasing necessary logistics for providing maternal health care services, providing salary for accountants to maintain the financial records, and to support voucher recipients that may require some additional discretional funds.

Table 16 shows that Taka 436,540 were allocated from the project for covering the costs of delivering the services covered by the voucher book. Over the course of the project, approximately 
78 percent (Taka 341,052) of these funds were spent on consultation fees, blood and urine tests, medicines, and transportation, and the remaining 22 percent (Taka 95,488) were deposited in the seed fund.

\section{Table 16: Cost of services provided}

\begin{tabular}{lcrrr}
\hline \multirow{2}{*}{ Type of services } & \multicolumn{3}{c}{ Cost of services } \\
\cline { 2 - 5 } & No. of recipients & Allocation & Expenses & Seed fund \\
\hline First ANC visit $(C F+T+T A)^{*}$ & 496 & 111600 & 74400 & 37200 \\
Second ANC visit $(C F+T+T A)$ & 286 & 64350 & 42900 & 21450 \\
Third ANC visit (CF + T + TA) & 137 & 20550 & 17125 & 3425 \\
Normal delivery (CF + M + TA) & 84 & 66040 & 55010 & 11030 \\
Complicated delivery (CF + M + TA) & 4 & 7600 & 5867 & 1733 \\
Caesarean delivery (CF + M + TA) & 13 & 91000 & 78000 & 13000 \\
Complications management & 16 & 29500 & 29500 & 0 \\
PNC (CF + TA) & 306 & 45900 & 38250 & 7650 \\
Total voucher recipients & $\mathbf{5 8 0}$ & $\mathbf{4 3 6 5 4 0}$ & $\mathbf{3 4 1 0 5 2}$ & $\mathbf{9 5 4 8 8}$
\end{tabular}

$\mathrm{CF}=$ Consultation fees, $\mathrm{T}=$ Tests, $\mathrm{TA}=$ Transport Allowance, $\mathrm{M}=$ Medicine

From the seed fund, Taka 46,066 were spent purchasing logistics and paying salaries of the accountants, leaving Taka 49,422 unspent in the seed fund. It is estimated that, on average, Taka 667 (US\$9.70) were spent for each of the 580 women using the vouchers. 


\section{CONCLUSIONS AND RECOMMENDATIONS}

This study was conducted to test the feasibility and effectiveness of introducing a voucher scheme for poor, rural women to improve utilization of ANC, delivery and PNC services from trained service providers.

Formation of district and upazila level coordination committees, in assistance with district and upazila level service providers and program managers, was effective for the implementation of project activities, especially for: i) selecting qualified private and NGO health facilities as referral clinics to perform caesarean deliveries; ii) establishing financial reimbursement mechanisms, and iii) monitoring readiness of health facilities to provide quality maternal health care services, the voucher distribution process and the financial disbursement procedure.

Involvement of local people through CSGs was one of the important factors for strengthening implementation of project activities. A total of 18 CSGs were formed in the project areas before introducing the interventions. CSGs were involved in validating poor pregnant women, strengthening the physical infrastructure of health facilities, and building accountability of service providers and fieldworkers for providing improved maternal health care services. Findings revealed that potential voucher recipients were identified by the fieldworkers and a total of 580 women were validated by the CSG members in their regular monthly meetings. The CSGs assisted MOHFW staff to improve the physical infrastructure of health facilities by cleaning inside and outside the facility and renovating the entrance. On average, 12 monthly meetings out of 18 were organized by the CSG members to identify problems and possible solutions for smooth implementation of project activities. In addition, they explored several service-related issues in their regular monthly meetings and informed to the respective fieldworkers for the remedy.

Observations at facilities indicated that service providers were available and the infrastructure of the health facility was favourable. There were adequate behavior change communication materials and the necessary equipment to provide quality maternal health care services. Service providers were observed maintaining privacy with clients during the consultations. A significant number of the voucher recipients reported receiving quality maternal health care services during the intervention period. Monitoring reports from the community support group monthly meetings indicate that the meetings were held in a participatory manner and specific issues were discussed. Apart from the Family Welfare Assistant, in most of the areas the male union parishad members played important roles in organizing meetings. Monitoring visits revealed that most of the union family planning committee meetings were not held due to the engagement of members in other priorities. However, when the interventions were being introduced they played an important role in strengthening the infrastructure of the health facilities.

The 21-day hands-on training session for the Family Welfare Visitors to perform normal deliveries at health and Family Welfare Centers was found appropriate. Three days training for the service providers and fieldworkers was reasonably effective for disseminating information on the importance of maternal health care issues and the process of administering the vouchers. This is an encouraging finding as it provides an opportunity for disseminating important information to the clients by fieldworkers during their routine household visits and voucher distribution. 
Findings from the endline survey revealed that knowledge on maternal health care issues, including life-threatening complications, sources of treatment for complications, place of safe delivery, intake of vitamin A capsule and duration of exclusive breastfeeding, had increased significantly compared to the baseline. The proportion of women who did not access any antenatal care services decreased from 21 to 11 percent and the proportion of women who received this service from a trained service provider increased from about 50 to 100 percent. Similarly, the proportions of women attending for first, second and third antenatal visits increased over time. A significant number of women received physical and medical examination facilities during antenatal care visits and immunization during pregnancy and supply of iron tablet/syrup also increased (from 63\% to $72 \%$ and $20 \%$ to $77 \%$ respectively).

Increasing the proportion of deliveries assisted by trained providers is essential to achieve the MDG of reducing the maternal mortality ratio. At baseline, trained providers attended only 5.5 percent of births, whereas at endline this proportion had increased to 22 percent. Similarly, the proportion of deliveries at health facilities increased to 18 percent from a baseline of 2.3 percent. The proportion of women who received treatment for complications also increased significantly over the intervention period.

The proportion of women who received postnatal care increased significantly to 60 percent at the endline; moreover, at the baseline, only one-fourth of women accessing postnatal care received it from trained providers, which increased to 100 percent at endline. The proportion of women was using Vitamin A capsule remained low and the majority of women exclusively breastfed their baby immediately after delivery.

Although the proportion of women using antenatal care, postnatal care, institutional deliveries and deliveries assisted by trained providers increased significantly, it is important to note that these proportions remained relatively low after the intervention. The majority of women received vouchers during the later stages of their pregnancy (85 percent received them during the third trimester), which was due to the short duration of the intervention period and so had less opportunity to avail ANC services.

The most frequently cited reasons for not delivering at a health facility were: no problems; labor pain started suddenly; no-one to accompany them to the facility; and fear. Similarly, the most frequently cited reasons for not accessing PNC services were: didn't face any problems; not sure about the system of voucher utilization; providers were reluctant to provide services; fear; and other service related-issues.

In-depth interviews revealed that women did not experience any problems in obtaining the voucher book from the fieldworkers. Overall, they expressed positive perceptions of the service quality and behavior of the providers. Women did not report facing any problems in utilizing the services in exchange for the vouchers and they received the fixed transport and medicine cost allowances. On average, 667 Taka (US\$9.70) was spent per case, which is reasonable and affordable.

Based on these findings, the following recommendations are made for scaling-up these activities in other areas of Bangladesh:

- Formation of coordination committees at district and upazila levels is essential to identify eligible health facilities and to establish reimbursement mechanism for the vouchers. 
- Community support groups can play crucial roles for validating pregnant women identified as poor, as well as for identifying problems and finding possible solutions to strengthen the physical infrastructure and performance of union-level health facilities.

- Strengthening health facility in terms of instruments/equipment, furniture and medicines are an encouraging factor leading to the availability of quality services and the increased number of clients at the facility.

- Hands-on training increases the confidence of Family Welfare Visitors to perform normal deliveries at the Health and Family Welfare Centers. Training for service providers and fieldworkers is essential to update their knowledge and skills on maternal health care services and for orienting them on the process of utilizing vouchers.

- The process of identifying poor pregnant women and distribution of the vouchers needs to begin early in a pregnancy to ensure that the woman can benefit from the full range of services covered.

- Strong commitment from the service providers and fieldworkers is essential to improve the utilization of maternal health care services. To reduce the workload of female paramedics, male paramedics can be encouraged to undertake physical and medical examinations during pregnancy care and record-keeping for vouchers can be simplified.

\section{DISSEMINATION AND UTILIZATION}

From the initial stages of the study, the utilization of the findings for scaling up the voucher scheme in other areas of the country was strategically targeted. A Project Coordination Committee was established, including members from the National Institute of Population Research and Training (NIPORT), Directorate of Family Planning, Directorate of Health, Ministry of Health and Family Welfare, Dhaka City Corporation, CIDA and UNFPA. This committee was involved at each stage of planning and implementation of the study. Committee members visited the study areas several times to monitor the implementation status of the project.

The findings of the study were shared on a regular basis with the project implementing partners. Two 'Research Updates' describing implementation processes, status of interventions and important lessons learned, were widely distributed. The findings were also shared with district, upazila and union level health and family planning staff and members of CSG. The findings have been disseminated to the community through CSG meetings.

The study findings have been presented at a national-level dissemination seminar where key stakeholders including local-level program managers and community members were present. Other stakeholders at this dissemination seminar were representatives of the Ministry of Health and Family Welfare, NIPORT, UNFPA, CIDA, DBRHCP partners, NGOs, policy-makers and program managers, so that lessons learned and tools developed from the project can be utilized and scaled up in other areas of the country. The findings were also presented at the annual meeting of American Public Health Association (APHA), Population Association of America (PAA) and to CIDA staff in Ottawa in October 2008. Initiatives are also underway to ensure the sustainability of the interventions through dialogue with the officials of the Ministry of Health and Family Welfare as well as different donors. 


\section{REFERENCES}

Bangladesh Bureau of Statistics (BBS). 2008. Statistical Year Book of Bangladesh 2007. Dhaka, Bangladesh: BBS.

Bhatia, M. R., C. A. K. Yesudian, A. Gorter, and K. R. Thankappan. 2006. "Demand side financing for reproductive and child health services in India." Economic and Political Weekly. 21 January: 279-294.

Borghi, J., A. Gorter, P. Sandiford, and S. Zoyla. 2005. "The cost-effectiveness of a competitive voucher scheme to reduce sexually transmitted infections in high-risk groups in Nicaragua." London: Infectious Disease Epidemiology Unit, London School of Hygiene and Tropical Medicine and Managua, Nicaragua: Instituto Centroamericano de la Salud.

Ensor, T. 2003. "Consumer-led demand side financing for health and education: An international review.” Dhaka, Bangladesh: World Health Organization.

Gertler, P. J. and S. Boyce. 2001. "An experiment in incentive-based welfare: The impact of PROGRESA on health in Mexico.” No 85, Royal Economic Society Annual Conference 2003 from Royal Economic Society.

Graham, W. J., J. S. Bell, and C. H. W. Bullough. 2001. "Can skilled attendance at delivery reduce maternal mortality in developing countries?" in Brouwere, Vincent De and Wim Van Lerberghe (eds). Safe Motherhood Strategies: A Review of the Evidence. Nationalestraat, Belgium: ITG Press.

Islam, M. K. 2003. "Health financing options for the poor: A national review." Dhaka, Bangladesh: World Health Organization.

Kelin, D., K. Zhang, and S. Tang. 2001. "A draft report on a MCHPAF study in China." Washington, World Bank.

Marchant, T., J. A. Schellenberg, T. Edgar, R. Nathan, S. Abdulla, O. Mukasa, H. Mponda, and C. Lengeler. 2002. "Socially marketed insecticide-treated nets improve malaria and anemia in pregnancy in southern Tanzania." Tropical Medicine \& International Health 7 (2): 149-158.

Ministry of Health and Family Welfare, Government of the People's Republic of Bangladesh. 2001. Bangladesh National Strategy for Maternal Health. Dhaka, Bangladesh: Ministry of Health and family Welfare, Government of the People's Republic of Bangladesh.

Mushi, A. K., J. R. Schellenberg, H. Mponda, and C. Lengeler. 2003. "Targeted subsidy for malaria control with treated nets using a discount voucher system in Tanzania." Health Policy Planning 18 (2): 163-71.

National Institute of Population Research and Training (NIPORT), Mitra and Associates, and ORC Macro. 2007. Bangladesh Demographic and Health Survey 2007. Dhaka, Bangladesh: NIPORT, Mitra and Associates and Calverton, Maryland, USA: ORC Macro.

National Institute of Population Research and Training (NIPORT), Mitra and Associates, and ORC Macro. 2005. Bangladesh Demographic and Health Survey 2004. Dhaka, Bangladesh: NIPORT, Mitra and Associates and Calverton, Maryland, USA: ORC Macro. 
National Institute of Population Research and Training (NIPORT), ORC Macro, Johns Hopkins University, and ICDDR,B. 2003. Bangladesh Maternal Health Services and Maternal Mortality Survey 2001. Dhaka, Bangladesh: NIPORT, ICDDR,B and Calverton, Maryland, USA: ORC Macro, Johns Hopkins University.

Rahman, L., U. Rob, S. Ahmed, M. Mahbub-ul-Anwar, and M. Rahman. 2006. "Voicing the community: A study for the community to identify and prioritize family planning and reproductive health problems." Dhaka, Bangladesh: Population Council.

Rahman, M. U. Rob, T. Kibria, and M. Rahman. 2008a. "Voucher scheme for poor, rural women to utilize pregnancy care.” DBRHCP Research Update 3. Dhaka, Bangladesh: Population Council.

Rahman, M. U. Rob, T. Kibria, and I. A. Hena. 2008b. "Experiences from implementation of maternal voucher scheme in rural Bangladesh." DBRHCP Research Update 5. Dhaka, Bangladesh: Population Council.

Research Training and Management International. 2006. "Demand-based Reproductive Health Commodity Project: Training Needs Assessment," presentation at the Dissemination Seminar on Identification of Operations Research Issues, organized by Population Council, Dhaka, Bangladesh. November 15.

Rob, U., M. M. Islam, M. Mahabub-ul-Anwar, A. Arifeen, M. N. Talukder, and L. Rahman. 2006. "Population and development: Pilot research at community level on linkages between reproductive health and poverty." Dhaka, Bangladesh: Population Council. 